\title{
Measuring Outdoor Air Intake Rates into Existing Buildings
}

\author{
${ }^{1}$ William J Fisk, ${ }^{1}$ Douglas P Sullivan, ${ }^{1,2}$ Sebastian Cohen, ${ }^{3}$ Hwataik Han \\ ${ }^{1}$ Environmental Energy Technologies Division \\ Indoor Environment Department \\ Lawrence Berkeley National Laboratory \\ Berkeley, CA \\ ${ }^{2}$ Worcester Polytechnic Institute \\ Worcester, MA \\ ${ }^{3}$ Kookmin University \\ Seoul, Korea
}

April 2009

This research was supported by the California Energy Commission through the San Diego State University Research Foundation under contract 54915A/06-03B through Contract No. DE-AC02$05 \mathrm{CH} 11231$ between the University of California and the U.S. Department of Energy. 


\title{
BUILDING ENERGY RESEARCH GRANT (BERG) PROGRAM
}

\author{
BERG FINAL REPORT
}

Measuring Outdoor Air Intake Rates into Existing Buildings - Final Report

BERG AWARDEE

William Fisk

Indoor Environment Department, Lawrence Berkeley National Laboratory (LBNL)

1 Cyclotron Road, 90R3058

Berkeley, CA 94720

Phone: (510) 486-5910

Email:wjfisk@lbl.gov

AUTHORS

William Fisk, Principal Investigator

Douglas Sullivan, Sr. Scientific Engineering Associate, LBNL Sebastian Cohen, Worcester Polytechnic Institute, Worcester, MA

Hwataik Han, Kookmin University, Seoul, Korea

Grant \#: 54915A0603B

Grant Funding: \$107,630

Term: October 1, 2007 - December 31, 2008

PIER Subject Area: Buildings End Use Energy Efficiency Program 


\section{Legal Notice}

This report was prepared as a result of work sponsored by the California Energy Commission (Commission). It does not necessarily represent the views of the Commission, its employees, or the State of California. The Commission, the State of California, its employees, contractors, and subcontractors make no warranty, express or implied, and assume no legal liability for the information in this report; nor does any party represent that the use of this information will not infringe upon privately owned rights. This report has not been approved or disapproved by the Commission nor has the Commission passed upon the accuracy or adequacy of the information in this report.

Inquires related to this final report should be directed to the Awardee (see contact information on cover page) or the BERG Program Administrator at (619) 594-1049 or email

berg@energy.state.ca.us. 


\section{Acknowledgments}

This research was supported by the California Energy Commission through the San Diego State University Research Foundation under contract 54915A/06-03B through Contract No. DE-AC0205CH11231 between the University of California and the U.S. Department of Energy. The authors thank David Faulkner for his assistance in ordering experimental components, David Dougan at EBTRON for technical advice and providing the electronic velocity sensors used in this research, and Mike Apte and Leon Alevantis for reviewing a draft of this document.

\section{Citation}

Fisk, W. J., D. Sullivan, S. Cohen, and H. Han. 2008. Measuring Outdoor Air Intake Rates into Existing Buildings- Final Report. California Energy Commission, PIER Buildings Energy Research Program. CEC-500-2008-xxxx. 


\section{Preface}

The Public Interest Energy Research (PIER) Program supports public interest energy research and development that will help improve the quality of life in California by bringing environmentally safe, affordable, and reliable energy services and products to the marketplace.

The PIER Program, managed by the California Energy Commission (Energy Commission), conducts public interest research, development, and demonstration (RD\&D) projects to benefit California.

The PIER program strives to conduct the most promising public interest energy research by partnering with RD\&D entities, including individuals, businesses, utilities, and public or private research institutions.

PIER funding efforts are focused on the following RD\&D program areas:

- Buildings End-Use Energy Efficiency

- Energy Innovations Small Grants

- Energy-Related Environmental Research

- Energy Systems Integration

- Environmentally Preferred Advanced Generation

- Industrial/Agricultural/Water End-Use Energy Efficiency

- Renewable Energy Technologies

- Transportation

Measuring Outdoor Air Intake Rates into Existing Buildings is the final report for the Measuring Outdoor Air Intake Rates into Existing Buildings project, contract number 54915A0603B conducted by Lawrence Berkeley National Laboratory. The information from this project contributes to PIER’s Buildings End-Use Energy Efficiency Program.

For more information about the PIER Program, please visit the Energy Commission's website at www.energy.ca.gov/pier or contact the Energy Commission at 916-654-5164. 


\section{Table of Contents}

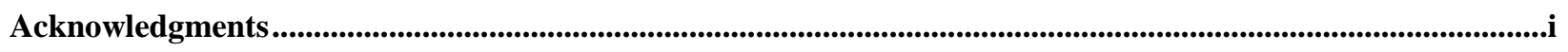

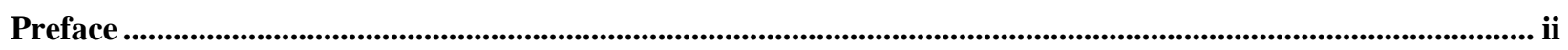

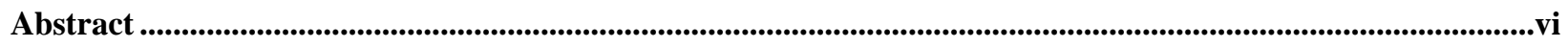

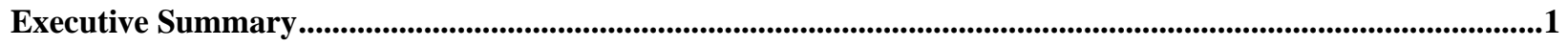

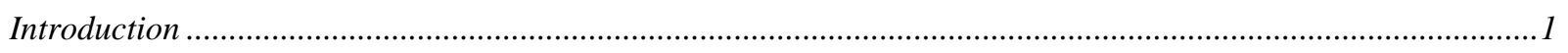

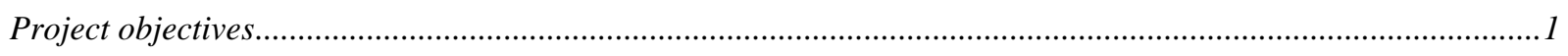

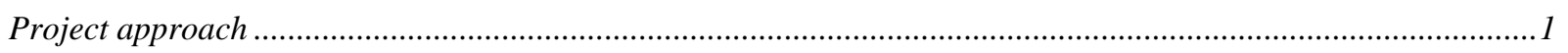

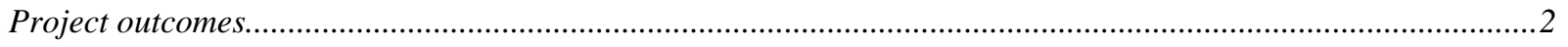

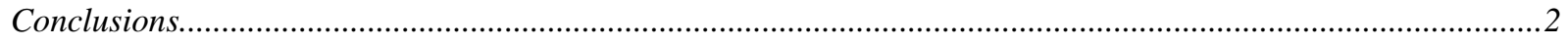

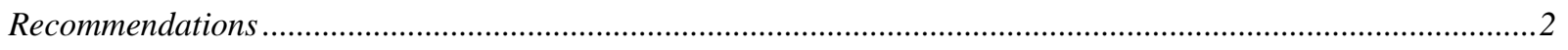

Public Benefits to California .......................................................................................................................

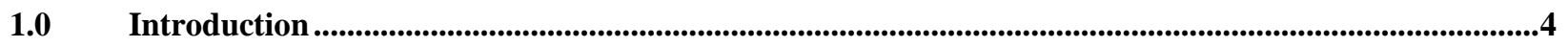

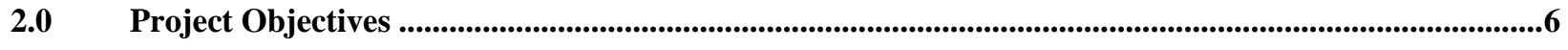

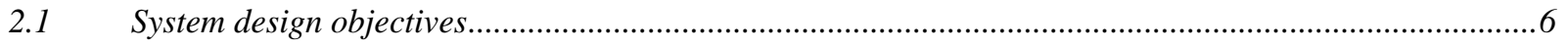

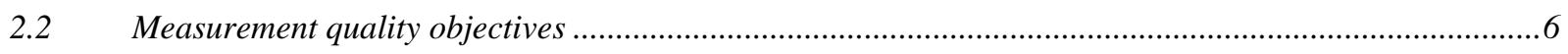

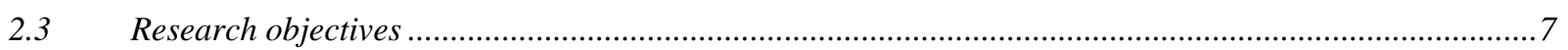

$2.4 \quad$ Research Documentation and Communication Objectives....................................................................

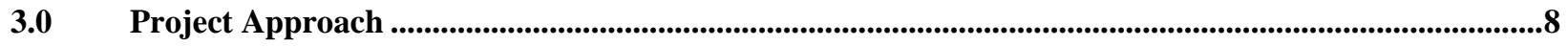

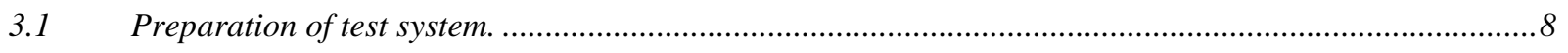

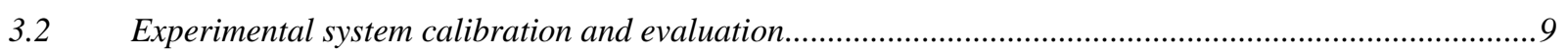

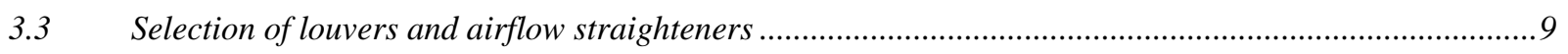

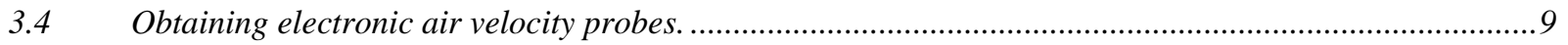

3.6 Assessing air velocity profiles using smoke injection and velocity traverses. ..........................................13

3.7 Conducting tests to evaluate the OA measurement systems ................................................................13

3.8 Documenting and communicating study results ....................................................................................14

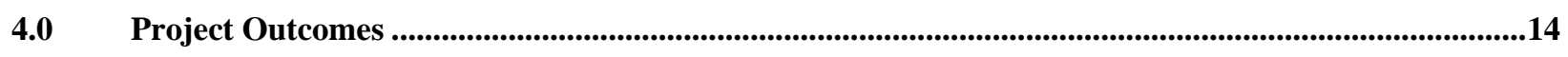

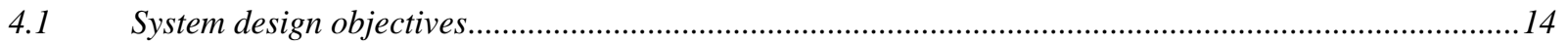

$4.2 \quad$ Measurement quality objectives ………......................................................................................

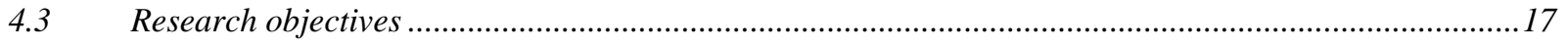

4.4 Research Documentation and Communication Objectives.................................................................24

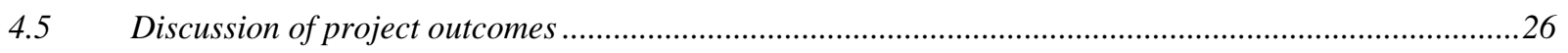




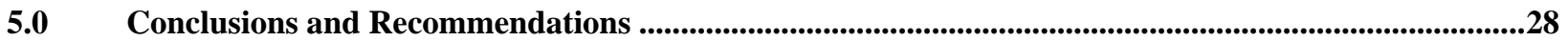

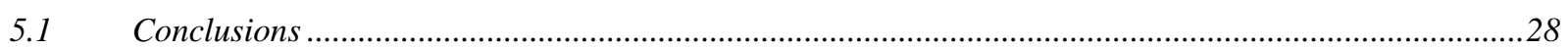

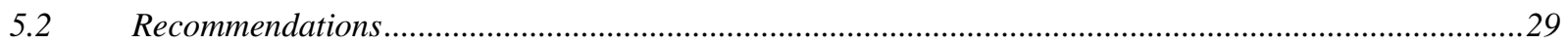

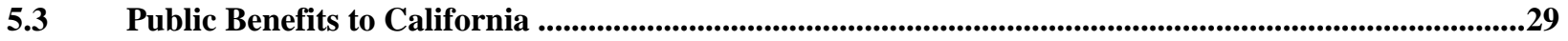

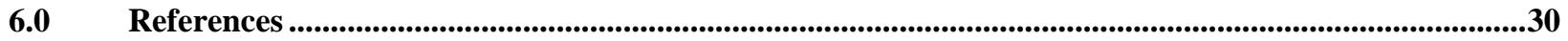

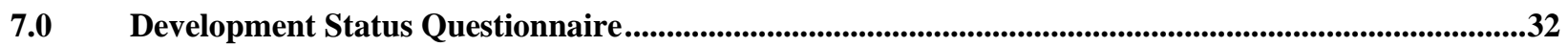




\section{List of Figures}

Figure 1. Illustrative diagram of test system............................................................................. 8

Figure 2. Side view cross section and outlet view of Arrow EA 64 louver................................... 11

Figure 3. Top cross section and outlet view of Greenheck EVH602............................................ 11

Figure 4. Side view cross section and outlet of Ruskin ELF375DX louver ................................. 12

Figure 5. Outlet view and top cross section of Ruskin EME6625 louver....................................... 12

Figure 6. Schematic illustration of a velocity probe containing one velocity sensor. ................... 13

Figure 7. Example of airflow patterns inferred from visualization of smoke flow. ...................... 16

Figure 8. Relationship of reference outdoor air flow with average velocity measured using electronic probes at louver outlets or between louver blades. ........................... 19

Figure 9. Errors in predicted OA flow rates with electronic velocity probes at louver outlets or between louver blades when using linear calibration equations. ................................20

Figure 10. Results of tests using velocity probes with nine or three air velocity sensors located behind airflow straighteners, and for reference, behind no airflow straightener. In all experiments, the inlet of the flow straightener was located 5 to 6 inch behind the outlet of the louver (depending on the louver thickness) and sensors were located 3 inch (dark columns) or 5 inch (light columns) behind the outlet face of the airflow straightener. The distance between the sensors and centerline of the outdoor air damper was 9.5 inch (dark columns) or 45 inch (light

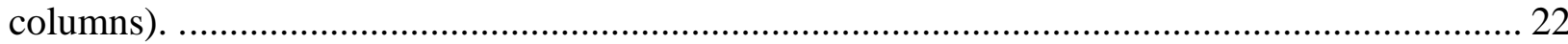

Figure 11. Average air velocity, using data from nine velocity sensors, versus reference flow from tests with airflow straighteners.

\section{List of Tables}

Table 1. List of recipients of a summary report from this research project. 25 


\begin{abstract}
Practical and accurate technologies are needed for continuously measuring and controlling outdoor air (OA) intake rates in commercial building heating, ventilating, and air conditioning (HVAC) systems. This project evaluated two new measurement approaches. Laboratory experiments determined that OA flow rates were measurable with errors generally less than 10 percent using electronic air velocity probes installed between OA intake louver blades or at the outlet face of louvers. High accuracy was maintained with OA flow rates as low as 15 percent of the maximum for the louvers. Thus, with this measurement approach HVAC systems do not need separate OA intakes for minimum OA supply. System calibration parameters are required for each unique combination of louver type and velocity sensor location but calibrations are not necessary for each system installation. The research also determined that the accuracy of measuring $\mathrm{OA}$ flow rates with velocity probes located in the duct downstream of the intake louver was not improved by installing honeycomb airflow straighteners upstream of the probes. Errors varied with type of upstream louver, were as high as 100 percent, and were often greater than 25 percent. In conclusion, use of electronic air velocity probes between the blades of OA intake louvers or at the outlet face of louvers is a highly promising means of accurately measuring rates of OA flow into HVAC systems. The use of electronic velocity probes downstream of airflow straighteners is less promising, at least with the relatively small OA HVAC inlet systems employed in this research.
\end{abstract}

Key Words: commercial building, control, HVAC, measurement, outdoor air, ventilation 


\section{Executive Summary}

\section{Introduction}

Ventilation is typically provided to commercial buildings by drawing outdoor air (OA) into heating, ventilating, and air conditioning (HVAC) systems, mixing the OA with recirculated indoor air, heating or cooling and dehumidifying the mixture, and supplying the conditioned air to occupied spaces. The OA is drawn into the HVAC system through an air intake louver system that typically has parallel metal blades with a geometry designed to remove rain drops and snow. Rates of ventilation may be varied with weather conditions above some minimum rate. Higher ventilation rates, i.e., higher rates of OA supply, reduce indoor concentrations of indoorgenerated air pollutants and are associated with decreased adverse health symptoms and improvements in some aspects of work and school performance. Building energy consumption increases as the minimum ventilation rate increases. Minimum ventilation rates are specified for various types of buildings in building codes and standards, including California's Title 24. The specified minimum ventilation rates are chosen to strike a balance between indoor air quality and energy concerns. Despite the importance of ventilation rates, existing data indicate that minimum ventilation rates are often poorly controlled, which is not surprising because few buildings have systems for continuous or even frequent (e.g., monthly) monitoring and adjustment of minimum ventilation rates. Consequently, the goal of this project was to identify a practical and accurate technology for real time measurement and control of outdoor air intake rates in many existing and new commercial building HVAC systems.

\section{Project objectives}

The main scientific objectives of this project were as follows:

1) Evaluate the accuracy of measuring OA flow rates using electronic velocity sensors installed at the outlet plane of air intake louvers or between the blades of air intake louvers.

2) Evaluate the accuracy of measuring OA flow rates using electronic velocity sensors installed downstream of honeycomb airflow straighteners which are located in ductwork between the air intake louver and the OA damper.

\section{Project approach}

Using a laboratory test system, the accuracy of measuring OA flow rates was determined when electronic air velocity sensors were installed at the outlet of air intake louvers, between the blades of air intake louvers, and downstream of honeycomb airflow straighteners which were located in ductwork between the air intake louver and the OA damper. Tests were performed using four different types of air intake louvers, with two types of honeycomb airflow straighteners, with a range of OA flow rates, and with different sensor locations. Initial tests using smoke to visualize airflow patterns and a movable hand-held air velocity instrument provided information for selecting the locations for installing the electronic air velocity sensors. 


\section{Project outcomes}

This research determined that OA flow rates should be measurable with errors generally less than 10 percent using electronic air velocity sensors installed between air intake louver blades or at the outlet face of louvers. To calculate the OA flow rates, system calibration parameters are needed from tests performed for each unique combination of louver type and velocity sensor location; however, such data should be attainable from only a few hours of testing within a laboratory setting. Measured accuracy remained high even when OA flow rates are minimized as they are during hot or severely-cold weather. Unlike many other measurement approaches, with this measurement approach, the HVAC systems does not need to have a costly separate OA intake section dedicated to the minimum OA supply. Measurement accuracy was similar with velocity probes between louver blades or at the outlet face of louvers. Given that velocity probe installation at the louver outlet face is simpler, this may be the preferred probe location particularly when the measurement system is added to existing HVAC systems.

The research also determined that installation of two types of airflow straighteners did not improve the accuracy of measuring OA flow rates when the electronic velocity sensors were installed in the air duct system between OA intake louvers and OA dampers (the damper is the device used to adjust OA flow rate). For the louver types and sizes employed, the errors in measured OA flow rates using this approach with airflow straighteners were as high as 100 percent and were often larger than 25 percent.

\section{Conclusions}

The use of electronic air velocity probes between the blades of OA intake louvers or at the outlet face of louvers is highly promising as a means of accurately measuring the rates of OA flow into HVAC systems. Test data are required for each unique combination of louver type and velocity sensor locations, but tests do not appear to be necessary for each system installation. If suitable system calibration data are provided by the velocity sensor manufacturers or some other entity, this measurement approach should be applicable to both new and existing building HVAC systems.

Installation of two types of airflow straighteners did not improve the accuracy of measuring OA flow rates when the electronic velocity sensors were installed in the duct system between OA intake louvers and OA dampers. The measurements accuracy was often poor with errors larger than 25 percent. Thus, at least for the small size OA intake systems employed in this research, this measurement approach is less promising than use of electronic air velocity sensors between the blades of OA intake louvers or at the outlet face of louvers.

\section{Recommendations}

Field studies are recommended to assess the long term accuracy of OA flow rate measurements using electronic velocity probes installed between the blades of OA intake louvers or at the outlet face of louvers. These field tests will also serve as a technology demonstration that will help to build demand for technology commercialization.

Test are recommended to determine if the values of the system calibration parameters required to determine OA flow rates from the measured air velocities vary with louver size. 
Commercial application of the results of this research depends upon the development of system calibration parameters for various types of louvers and sensor locations. The development of such data and the development of suitable sensor installation hardware is recommended to the private sector, e.g. to manufacturers of suitable velocity sensors.

\section{Public Benefits to California}

This research has identified a highly promising approach for accurately measuring OA flow rates into existing and new commercial building HVAC systems. This measurement approach could be used in conjunction with existing building control systems to improve the control of the amount of OA ventilation provided to buildings. If the measurement approach is commercialized and significantly deployed, the resulting improvements in control of building ventilation rates will save energy because most existing buildings appear to be over-ventilated relative to building code requirements and because the heating and cooling of ventilation air consumes energy. The energy savings will help California achieve its goal of reducing emissions of greenhouse gases. In addition, improved indoor air quality and occupant health are expected when the measurement technology is utilized in buildings that are currently under-ventilated relative to code requirements. The annual technical potential energy savings from application of this technology in all California commercial HVAC systems with a capacity greater than 10 tons was estimated to equal 780 GWh of electricity and 20 million therms of gas; however, this estimate has a high uncertainty. 


\subsection{Introduction}

Ventilation is typically provided to commercial buildings by drawing outdoor air (OA) into HVAC systems, mixing the OA with recirculated indoor air, thermally conditioning the mixture, and supplying the conditioned air to occupied spaces. Except during mild weather, energy is used to heat or cool and dehumidify the OA, thus, HVAC system energy consumption increases as the ventilation rate increases. Nationally, about 1 quad of energy is used for ventilation in the commercial stock, out of 5.2 quads total for heating, cooling, and ventilation (Department of Energy 2006). In California, a similar proportion of HVAC energy is expected to be used for building ventilation.

Minimum ventilation rates are specified for various types of buildings in building codes and standards, including California's Title 24. For example, Title 24 requires $0.15 \mathrm{cfm} / \mathrm{ft}^{2}$ in offices, or $15 \mathrm{cfm}$ per person with the assumed typical occupant density. The minimum ventilation rates are chosen to strike a balance between indoor air quality and energy concerns. Higher ventilation rates reduce indoor concentrations of indoor-generated air pollutants and have been shown in research to be associated with improved perceived air quality, reduced adverse health symptoms, and improvements in some aspects of work and school performance (Seppanen, et al. 1999; Seppanen and Fisk 2006; Wargocki and Wyon 2007). On the other hand, higher minimum ventilation rates increase building energy consumption, energy costs, and peak energy demands.

Despite the importance of ventilation rates, existing data indicate that minimum ventilation rates are often poorly controlled. The most representative data from U.S. commercial buildings are from a survey of 100 representative office buildings (Womble, et al. 1996) with 40 measurements taken when ventilation rates should be at the minimum because outdoor temperatures were greater than $75^{\circ} \mathrm{F}$. From the carbon dioxide $\left(\mathrm{CO}_{2}\right)$ data collected from these 40 buildings, the average minimum ventilation rate (Fisk et al. 2005a) was $28 \mathrm{cfm} /$ occupant -almost twice the minimum ventilation rate per person specified in Title 24 for offices. A portion of the excess ventilation is due to buildings having occupant densities less than the design density, but poor control of ventilation air supply is also a major factor. Despite the high average minimum ventilation rate, in 12 percent of the buildings ventilation rates were below Title 24 requirements. While offices are usually over-ventilated relative to code requirements, a survey (CARB 2004) indicates that approximately half of elementary-level classrooms in California have less ventilation than specified in codes. These two surveys provide clear evidence that ventilation rates are poorly controlled in many existing commercial buildings. Overall, we expect buildings to be over-ventilated relative to codes, because the floor area of office buildings and other commercial buildings with similar HVAC designs is much greater than the floor area of classrooms (ITRON 2006).

It is not surprising that ventilation rates are poorly controlled. Few buildings have systems for continuous or even frequent (e.g., monthly) monitoring and adjustment of minimum ventilation rates. In addition, minimum ventilation rates in codes are tied to occupancy but in most buildings the rates of outdoor air supply are not modulated in response to changes in occupancy. The typical practice is to have an air balance company measure the OA flow during initial building commissioning and occasionally, e.g., every several years, thereafter and adjust the dampers for OA, recirculation air, and exhaust air to obtain the desired minimum rate of OA supply. 
However, accurately measuring OA airflow into HVAC systems is technically challenging even for researchers with special instrumentation and considerable time. In addition, the OA flows may vary as the HVAC supply air flow rates are modulated and because the minimum damper positions set by the air balance professional may be changed by building operators or due to wear or failures in the damper actuators and linkage. Another fairly common practice used in a significant number of buildings is called fan tracking and relies on the difference between supply and return air flow rates to estimate the OA entry rate. Research (Kettler 1995; Kettler 2000) shows that the fan tracking often results in large errors in the estimated OA flow rates. In a third practice for controlling ventilation, called demand controlled ventilation (DCV), $\mathrm{CO}_{2}$ concentrations, indicative of ventilation rate per occupant, are measured in occupied spaces or return ducts and $\mathrm{OA}$ supply rates are modulated to maintain $\mathrm{CO}_{2}$ concentrations below a target. However, DCV does not control of the minimum ventilation rates per unit floor area specified in Title 24 and ASHRAE Standards. The $\mathrm{CO}_{2}$ signal used by DCV systems also lags changes in occupancy, sometimes by hours. During the first few hours of occupancy, the $\mathrm{CO}_{2}$ sensor may provide no useful information on ventilation rate. Finally, studies of $44 \mathrm{CO}_{2}$ sensors in California commercial buildings (Fisk et al. 2006) makes it clear that DCV suffers from $\mathrm{CO}_{2}$ measurement errors, which were greater than 300 parts per million in many cases.

An additional approach for gaining better control of building ventilation rates, and the focus of this paper, is to use technologies that measure, with reasonable accuracy and in real-time, the rates of OA flow into HVAC systems. The measurements of flow rates can be used with existing control systems, and, if desired, in conjunction with DCV, to regulate rates of outdoor air supply. Four such technologies were previously evaluated in laboratory and field studies (Fisk et al. 2004; Fisk et al. 2005a; Fisk et al. 2005b; Fisk et al. 2005c). Some of the measurement systems evaluated in the prior research yielded OA flow rates with large errors because the measurement systems did not account for the complex air flow patterns that occur downstream of OA intake louvers and that vary with louver type. Some technologies were reasonably (e.g., 20\%) accurate in some situations, but none was suitable for broad scale use in the typical existing or new commercial building HVAC systems. Most of the technologies had pressure-based velocity sensors with very small pressure signals at the typical minimum OA intake velocities encountered HVAC systems with economizers. These low pressures cannot be measured accurately with the pressure transducers used in buildings. Some of these systems could provide reasonably accurate measurements of minimum OA flow rates in HVAC systems with separate intake louvers and dampers for the minimum OA supply flow and for the economizer flow; however, such an intake configuration is not common in existing buildings and retrofits to produce such an intake system will often be prohibitively expensive. Even in new construction, space constraints often make it impractical to provide a separate OA intake system for the minimum OA supply. Consequently, the prior research indicated a strong need for practical technologies for measurement of OA intake rates in existing and new buildings.

Given this background, the goal of this project was to identify a practical and accurate technology for real time measurement and control of outdoor air intake rates in many existing and new commercial building HVAC systems and, thus, to enable reduced energy consumption for heating and cooling of ventilation air. The accuracy of two measurement approaches, viewed as promising given the results of the prior research (Fisk et al. 2005a; Fisk et al. 2005b), was evaluated. In one of these measurement approaches, electronic velocity sensors are utilized 
between the blades of air intake louvers or at the outlet face of louvers. One of the existing technologies evaluated previously (Fisk et al. 2005a) employed pressure-based velocity sensors at the louver outlet and this technology performed well when air velocities were sufficient for accurate measurements. By using electronic velocity sensors that can accurately measure lower air velocities than pressure-based sensors at the louver outlet, a more broadly applicable measurement system was envisioned. In the second measurement approach, the electronic velocity sensors were utilized downstream of honeycomb airflow straighteners installed between the air intake louver and the outdoor air damper.

This research project addressed multiple research issues identified for the PIER Building Energy Research Program (see www.energy.ca.gov/pier/buildings), including the following:

- The research focused on a technology that addresses cooling energy in the hotter inland areas of California (Issue 1)

- The research addressed the need for tools for responding to real time electricity pricing (Issue 2), as temporary reductions in ventilation rates are a response option.

- The research focused on an energy savings measure that should be lower cost (Issue 3) than many energy savings technologies. The hardware requirements would be modest and the hardware is readily integrated with most existing control systems.

- The research focused on existing buildings (Issue 5) requiring a modest investment of hardware and integration with existing control systems.

\subsection{Project Objectives}

Performance objectives from the statement of work are provided below, organized onto three general categories of objectives.

\subsection{System design objectives}

Objective 1. Louvers will have a blade spacing compatible with the velocity probes

Objective 2. Horizontal and vertical blade louvers will be obtained.

Objective 3 Louver free area as a percent of nominal face area will vary over the typical range, e.g. 40 percent to 60 percent.

Objective 4. Probes will have dimensions and a sensitivity consistent with measurement objectives.

Objective 5. Probes systems, e.g., number of probes and sensors, will be considered marketable from a cost perspective, based on a consultation with the manufacturer.

Objective 6. Flow straighteners will have a predicted pressure drop less than 0.14 inch of water.

Objective 7. The most promising probe locations for probes installed inside or at the outlet face of louvers will be selected.

Objective 8. Visual observations of smoke flow will confirm that flow straighteners actually straighten the airflow.

\subsection{Measurement quality objectives}

Objective 9. Test system leakage will be less than 2 percent of the minimum air flow rates expected in practice. 
Objective 10. Pressure differences measured with the electronic transducer, after calibration factors are applied as needed, will be within \pm 0.008 inch of water of the pressures difference measured with the micromanometer.

Objective 11. Flow rates measured by the reference flow meter and by the Pitot tube traverse will agree within 6 percent.

\subsection{Research objectives}

Objective 12. The accuracy of OA flow measurements will be quantified for the various experimental configurations with velocity probes between louver blades or at the louver outlet using the following equation

$$
Q_{O A}=V_{A V G} K A_{F R E}
$$

where $Q_{O A}$ is the OA flow rate, $V_{A V G}$ is the average velocity from the electronic sensors, $K$ is a constant determined from test results, and $A_{F R E E}$ is the free area of the louver - a parameter provided by louver manufacturers. Determine the calibration factors; i.e., values of $K$ in equation 1, that best fit data from the experiments described above using probes in conjunction with louvers. Develop estimates of the errors in OA flow rate measurement resulting when a single value of $K$ is used for a range of $\mathrm{OA}$ flow rates and when $K$ obtained from experiments with one louver-probe combination is applied to a second version of the same louver type. Quantify the repeatability of accuracy estimates and $K$ values from the repeated tests.

Objective 13. The accuracy of OA flow rate measurements for the various experimental configurations with airflow straighteners will be quantified using the following equation

$$
Q_{O A}=V_{A V G} A_{\text {DUCT }}
$$

where $Q_{O A}$ is the OA flow rate, $V_{A V G}$ is the average velocity from the electronic sensors and $A_{D U C T}$ is the cross sectional area of the duct located between the air intake louver and OA damper where the airflow straightener and velocity sensors are installed.

Objective 14. Assess the change in accuracy, if any, in two OA flow measurement configurations, when air is recirculated.

\subsection{Research Documentation and Communication Objectives}

Objective 15. Mail a report from this research to at least $20 \mathrm{HVAC}$ firms and/or manufacturers of OA flow measurement technologies.

Objective 16. Hold at least one in-person or conference call discussion with CEC staff responsible for related portions of Title 24. 


\subsection{Project Approach}

\subsection{Preparation of test system.}

Figure 1 is a schematic diagram of the test system used for this research. The laboratory test system has a changeable OA intake louver system, air recirculation ductwork, a fan, dampers, and a precision "reference" airflow meter in the exhaust airstream. The reference airflow meter (Brandt Model NZP1031-10"-1-CF ) has a built-in airflow straightener, a nozzle, a Pitot tube velocity sensor at the nozzle outlet, and a manufacturer's rated accuracy of \pm 0.5 percent. The recirculation flow rates are measured with an estimated \pm 20 percent accuracy based on the pressure drop across an iris-style damper (Aeroflo, Inc 16” Iris Damper), relying on the manufacturer's calibration. Highly accurate measurements of recirculation air flow rates were not important for these tests and most tests involved no recirculation. The pressure signal of the reference flow meter was measured with an electronic pressure transducer (Energy Conservatory Model APT 8) calibrated three times during the study.

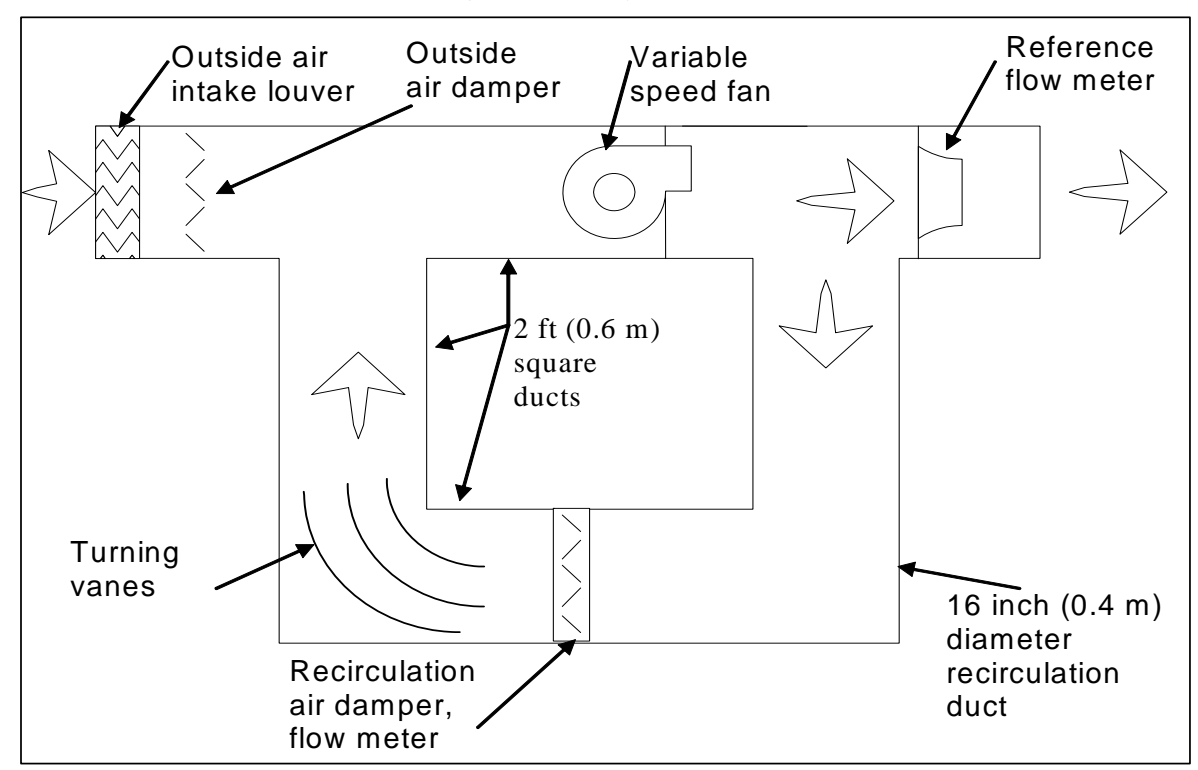

Figure 1. Illustrative diagram of test system. In practice, there are 12 diameters of straight duct upstream and 6 diameters of straight duct downstream of the reference flow meter.

Because the system is sealed to reduce air leakage to a negligible level, the flow of OA into the test system equals the exhaust airflow rate, which is measured with the reference airflow meter. Thus, the accuracy of the OA measurement technology is determined by comparison to the flow rate measured with the reference airflow meter, and the percentage measurement error (\%error) is calculated from:

$\%$ error $=100 \%\left(Q_{P}-Q_{R E F}\right) / Q_{R E F}$

where $Q_{P}$ and $Q_{R E F}$ are the OA flow rates predicted from the measurement technology being evaluated and from the reference flow meter, respectively. 


\subsection{Experimental system calibration and evaluation}

The experimental system was assembled, checked for air leakage, and instruments were calibrated. To perform the leakage test, the inlet and outlet of the test system were capped, and the airflow required to pressurize the system by 2 inch water, which exceeds that encountered during subsequent experiments, was measured using a dry test meter.

The calibration of the pressure transducer used with the reference air flow meter was checked on three occasions using an electronic micro-manometer as the calibration reference. The calibration check was performed at ten values of pressure spanning the range encountered in the experiments.

Before initiating tests of the OA measurement systems, two flow rates measured with the reference flow meter were compared to two flow rates measured via a standard Pitot tube traverse performed according to instructions from the manufacturer of the Pitot tube with ten Pitot tube locations.

\subsection{Selection of louvers and airflow straighteners}

Four air intake louvers and two airflow straighteners were selected and purchased for the experiments. The studied utilized more louvers than airflow straighteners because louvers are more variable in design and because the use of velocity sensors within louvers or at the louver outlet was considered more promising. Two louvers had horizontal blades and two had vertical blades. Figures 2- 5 depict the louver geometries. All louvers had a factory-installed bird screen at the louver outlet. The manufacturers' published free areas of the louvers ranged from 30 percent to 48 percent of the nominal louver face area. The "fine" airflow straightener had honeycomb shaped cells with a 0.125 inch dimension between parallel sides of the cells and was 1.25 inch thick in the direction of airflow. The "coarse" airflow straightener had honeycomb shaped cells with a 0.375 inch dimension between parallel sides of the cells and was 2.5 inch thick in the direction of airflow. In experiments using velocity probes between louver blades or at the outlet face of louvers, the inlet face of the louver was 29.5 inch from the centerline of the OA damper. In experiments employing airflow straighteners, the outlet of the airflow straightener was located 15 inch downstream of inlet of the louver and the centerline of the OA damper was either 14.5 or 50 inch downstream of the outlet of the airflow straightener.

\subsection{Obtaining electronic air velocity probes.}

Twelve air velocity probes, 2.8 inch long and 0.75 inch in diameter, each with a single sensor that uses thermal dispersion anemometry, were provided for the study by EBTRON Inc. These probes are depicted schematically in Figure 6. The sensors are designed to measure the range of air speeds encountered in HVAV systems and probes containing multiple sensors are used commercially to measure flow rates in the ducts within HVAC systems including OA flow rates by placing probes downstream of air intake louvers and upstream of OA dampers. Thus, the present study is an evaluation of using the EBTRON probes in a non-standard manner.

The minimum diameter probes available from EBTRON were used in the study in order to minimize the blockage of the airflow path air when probes were installed between louver blades. 
EBTRON suggested that the use of probes with only a few sensors would be the typical practice for the 24 inch by 24 inch air intake systems employed in the research. The experiments employed four to 12 installed sensors; however, in many cases the calculated OA flow rates were based on data from only a subset of the sensors. For use in experiments, multiple of the 2.8 inch long probes containing a single velocity sensor were connected together with cylindrical tubing to produce longer probes containing up to four velocity sensors. To the degree possible, probes were installed so that velocity sensors were located in centers of equal areas of airflow passages. The exception was as follows -- the upper probe installed at the outlets face of the ELF375DX louver which was moved upward by 0.5 inch to capture the maximum air speeds. Probes were rotated to yield the maximum air speed at their installed location.

The EBTRON probes were factory calibrated at multiple flow rates, are designed to correct for air temperature variations, and have a rated sensor accuracy of \pm 2 percent. Before use, the air speeds from the EBTRON probes were compared to airspeeds, ranging from 34 to $1970 \mathrm{ft} / \mathrm{min}$, measured with a new, factory calibrated thermal anemometer (Alnor Model AVM 440 with rated accuracy of \pm 3 percent of reading or $\pm 3 \mathrm{ft} / \mathrm{min}$ ) with a calibration traceable to the National Institute of Standards and Technology (NIST). Given the uncertainties in velocity probe placement, the accuracy of data collected with the thermal anemometer may be poorer than \pm 3 percent, thus, this sensor inter-comparison was primarily intended to assess whether the EBTRON probes were performing correctly. Considering the air speed range (100 to 1300 $\mathrm{ft} / \mathrm{min}$ ) encountered in subsequent testing, for all EBTRON probes, the relationship with the air speed measured using the thermal anemometer was highly linear with least squares fitting of equations to the data yielding slopes of 0.95 to 1.08 , zero offsets of -1 to $+27 \mathrm{ft} / \mathrm{min}$ and $\mathrm{R}^{2}$ values of 1.00. On average, the EBTRON probes gave a 5 percent larger air speed than the thermal anemometer.

Figures 2-5 depict the resulting locations of the four to 12 velocity sensors installed between louver blades or at the outlet face of louvers. Probes at the louver outlet were attached to the bird screens with nylon straps -- the type commonly used to hold electrical wiring in bundles although metal clips might be necessary to keep probes stationary in actual long-term deployments. Small sections of the bird screen were removed so that wires in the screen were not located directly in front of velocity sensors. Probes were installed between louver blades through holes drilled through the sides of louvers; however, special installation hardware could be developed by probe suppliers to make holes in the louver unnecessary. No experiments were performed with probes between the blades of the Ruskin EME6625 louver because, with the small louver blade spacing, the probes would have blocked most of the airflow passages. When probes were installed downstream of airflow straighteners, three probes were used, each with three velocity sensors, and the probes were located three or five inch downstream of the outlet of the airflow straightener. Average velocities were calculated using velocity data from all installed sensors and from subsets of sensors located in the centers of equal area. 

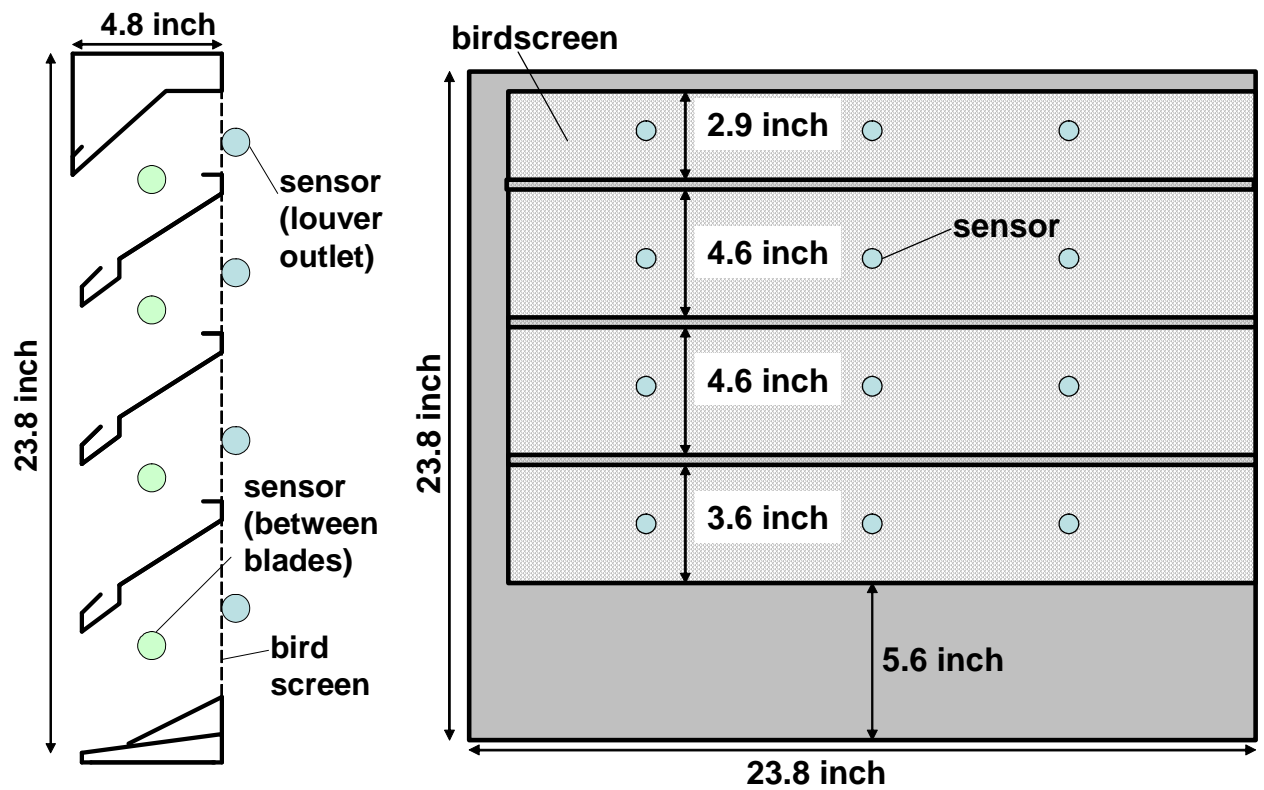

Figure 2. Side view cross section and outlet view of Arrow EA 64 louver with sensor locations.
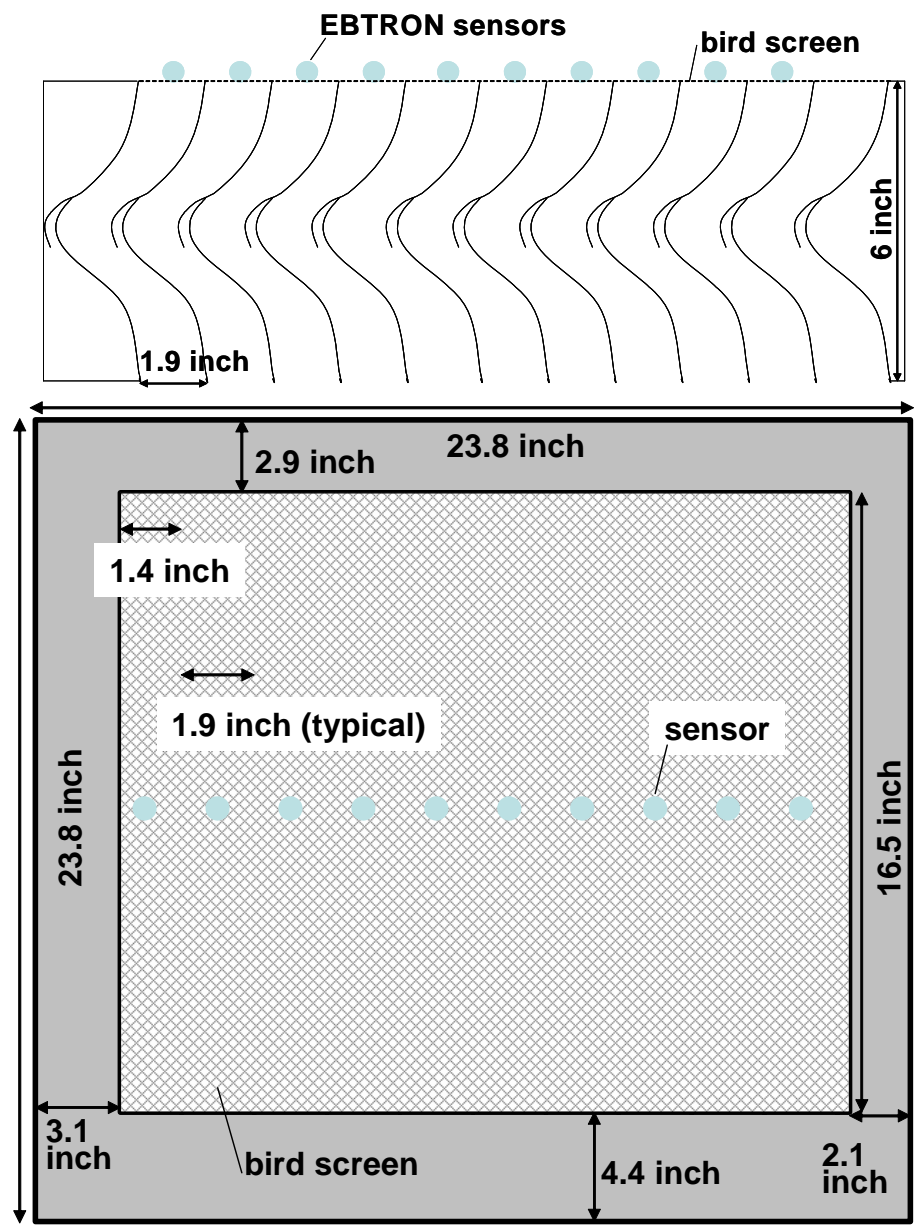

Figure 3. Top cross section and outlet view of Greenheck EVH602 louver with sensor locations. 

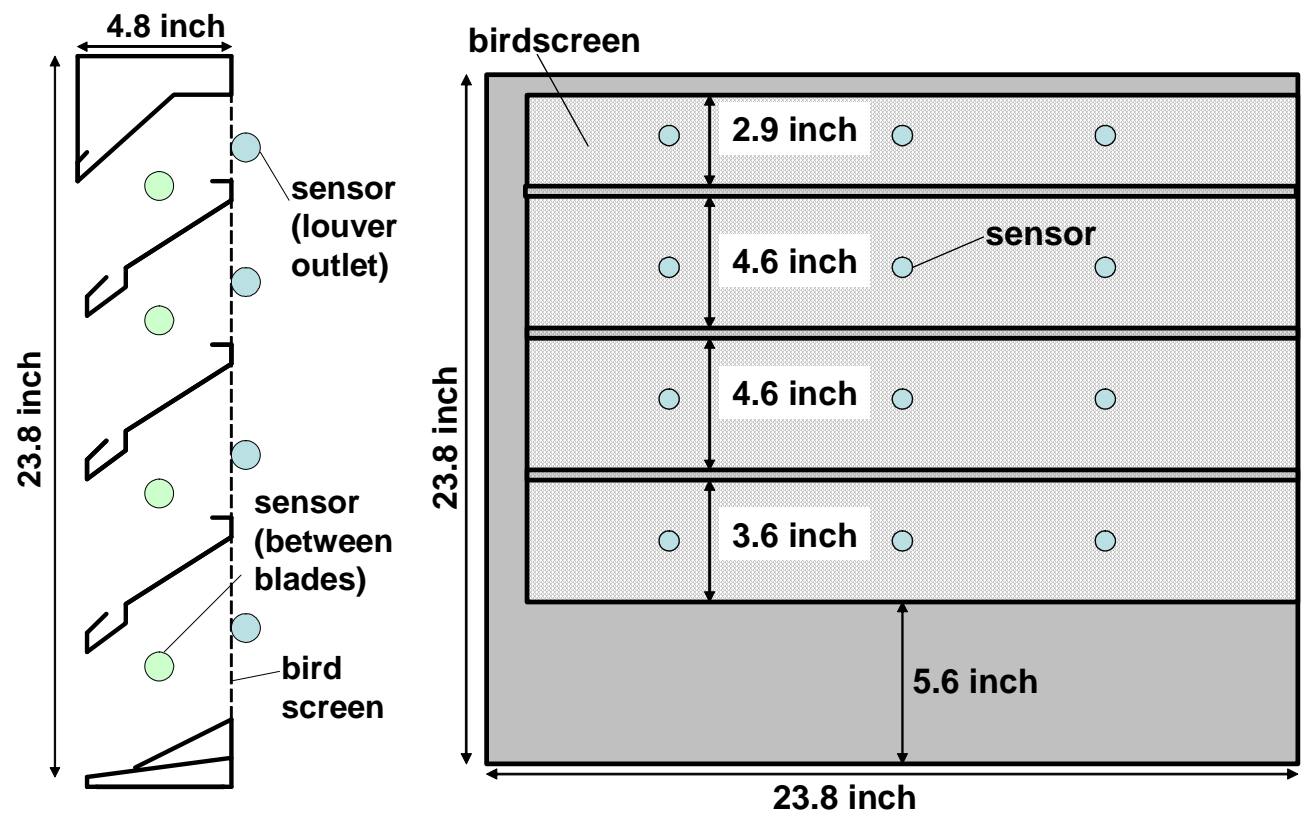

Figure 4. Side view cross section and outlet of Ruskin ELF375DX louver with sensor locations.
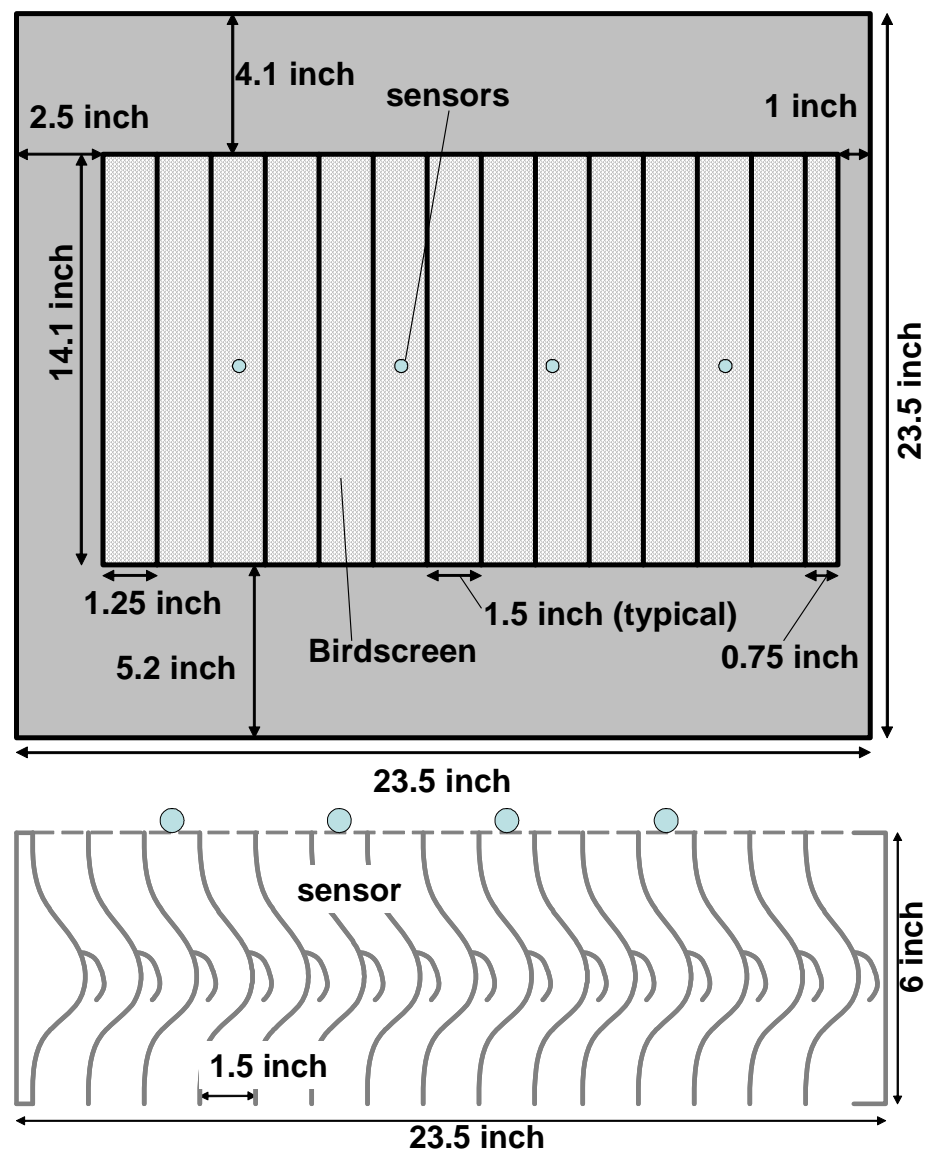

Figure 5. Outlet view and top cross section of Ruskin EME6625 louver with sensor locations. 


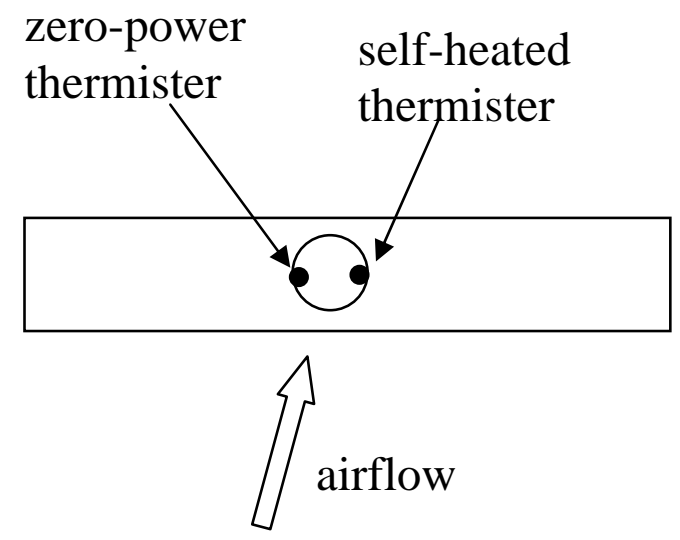

Figure 6. Schematic illustration of a velocity probe containing one velocity sensor.

\subsection{Assessing air velocity profiles using smoke injection and velocity traverses.}

To provide qualitative information for selecting EBTRON velocity sensor locations, smoke was injected at various locations in the test system. Observation of the smoke flow through a transparent window in a duct wall provided a qualitative indication of airflow patterns.

To provide further information for selection of EBTRON probe locations, the hot-wire thermal anemometer was used to map air speeds exiting the airflow channels created by adjacent louver blades and to measure air speeds at locations between louver blades.

\subsection{Conducting tests to evaluate the OA measurement systems}

To evaluate the OA measurement systems, the EBTRON probes, louvers, and airflow straighteners were installed as described above, OA flow rates were varied from approximately 15 percent of the maximum recommend flow rate for the louver (the maximum flow rates are based on rain penetration tests) to approximately the maximum recommend flow while logging $Q_{R E F}$ and the velocities indicated by the electronic sensors. At each test condition, data were collected every five seconds for six minutes. The four different air intake louvers and two different honeycomb airflow straighteners were employed during the testing. Most experiments were performed without air recirculation in the test system as prior research (Fisk et al. 2005b) had indicated that recirculation did not affect accuracy of OA flow measurements as long as a small (0.04 inch water) pressure drop was maintained across the OA damper - a criterion met in all tests in this series. The six-minute-averages of air speeds obtained from all installed EBTRON sensors or from subsets of installed EBTRON sensors were computed. The coincident six-minute-average flow rates through the reference air flow meter were also calculated with a small correction for elevation at the test site, per the manufacturer's instructions. The test system was located in a thermally conditioned indoor space thus the louver was not exposed to winds.

Using data collected with velocity probes between louver blades or at the outlet face of louvers, average air speeds measured with the EBTRON probes were plotted versus the measured reference OA air flow rates, and linear equations were fitted to the data using least-squares fitting routines to determine values of :" $m$ " and " $b$ " as defined in the following equation

$V_{A V G}=m Q_{R E F}+b$ 
where $V_{A V G}$ is the average velocity from the EBTRON probes. Predicted OA flow rates $\left(Q_{P}\right)$ were then calculated from equation 5 using the $m$ and $b$ "system calibration parameters" as follows

$$
Q_{P}=\left(V_{A V G}-b\right) / m
$$

Errors were then calculated using equation 3.

The original plan, from the research proposal, of using an equation with the form of equation 1 was not applied because values of " $b$ " were often substantially different from zero (equation 1 would apply only if $b$ was negligibly different from zero).

Using data collected with EBTRON probes downstream of airflow straighteners, equations 2 and 3 were used to calculated $Q_{P}$ and \%error as originally planned.

\subsection{Documenting and communicating study results}

A summary report, shorter than this final report, describing the study methods and results was written and distributed to 20 HVAC firms or applicable sensor manufacturers. Comments received from recipients are summarized later in this report. The summary report was also provided to a Ms. Martha Brook a Sr. Mechanical Engineer from the California Energy Commission who works on Title 24 Standards. The report was discussed with Ms. Brook via a telephone call and her main feedback is summarized later in this report

\subsection{Project Outcomes}

This report section is organized according to the sponsor's required format for final reports, with outcomes provided for each of the "performance and cost objectives" listed in a table within the statement of work. Parts of this section would more traditionally be included within the description of the research approach.

\subsection{System design objectives}

Objective 1. Select louvers with a blade spacing compatible with the velocity probes

By design, the project utilized velocity probes from EBTRON, Inc. These probes have a minimum diameter of 0.75 inch, thus, the louver blade spacing must be larger than 0.75 inch so that the probes fit between louver blades or at the louver outlet without blocking all or most of the airflow passage. Louvers were selected considering this constraint and the other louver selections objectives described subsequently. The spacing between blades in the louvers selected for use in the study was 4.0 inch, 2.0 inch, 5.09 inch, and 1.5 inch for the Arrow EA64, Greenheck EVH602, Ruskin ELF 375DX, and Ruskin EME6625 louvers, respectively. This spacing was judged adequate for installation of the probes at the outlet face of all louvers and between blades of all but the Ruskin EME6625 louver.

Objective 2. Obtain horizontal and vertical blade louvers. 
Two horizontal and two vertical blade louvers were used in the experiments.

Objective 3. Select louvers with free area as a percent of nominal face area that varies over the typical range, e.g. $40 \%$ to $60 \%$.

Fifteen louvers were considered as candidates for use in the experiments. The average free area of these 15 louvers as a fraction of nominal face area was 0.40 with a range of 0.30 to 0.50 . For the louvers employed in the experiments, the ratio of free area to nominal face area ranged from 0.30 to 0.48 .

Objective 4. Select probes with dimensions and a sensitivity consistent with measurement objectives.

The minimum diameter probes available from EBTRON were used in the study in order to minimize the blockage of the airflow path air when probes were installed between louver blades. The probe diameter was 0.75 inch which enabled probes to be installed downstream of all four louvers, downstream of the two airflow straighteners, and between the blades of three out of four louvers.

The EBTRON probes are designed and marketed for measuring the air speeds encountered in HVAC systems including the OA intake sections of these systems. Product literature gives a velocity range of zero to $5000 \mathrm{fpm}$ with an accuracy of $\pm 2 \%$ of the reading. The velocities measured ranged from approximately 100 to $1300 \mathrm{fpm}$, thus, the predicted maximum percentage error in air velocity measurement was 2 percent, even at the lowest air velocity.

Objective 5. Select probes systems, e.g., number of probes and sensors, considered marketable from a cost perspective, based on a consultation with the manufacturer.

EBTRON suggested that the use of probes with only a few sensors would be the typical practice for the 24 inch by 24 inch air intake systems employed in the research. The experiments employed four to 12 installed sensors; however, in many cases the calculated OA flow rates were based on data from only a subset of the sensors.

Objective 6. Obtain flow straighteners with a predicted pressure drop less than 0.14 inch of water.

Product literature for the airflow straighteners did not include pressure drops, thus, pressure drops were measured. Estimated airspeeds downstream of the airflow straighteners, i.e., air flow rates divided by the cross sectional area of the duct, ranged from approximately 75 to $325 \mathrm{fpm}$. The measured pressure drops of the fine airflow straightener were 0.013 , and 0.025 inch of water with airspeeds of 200, and $300 \mathrm{fpm}$, respectively. The measured pressure drops of the coarse airflow straightener were 0.007 , and 0.015 inch of water at with airspeeds of 200 and $300 \mathrm{fpm}$. At lower air velocities, the pressure drops of the airflow straighteners were too small for accurate measurement. 
Objective 7. Select the most promising probe locations for probes installed inside or at the outlet face of louvers.

As in our prior research (Fisk et al. 2005b), the smoke flow patterns indicated that a large eddy often forms downstream of the louver and upstream of the OA damper and that smaller eddies form immediately downstream of the outer edges of louvers as depicted in Figure 7. No eddies were evident at the outlet face of louvers at positions equal distant between adjacent louver blades, which was one of the planned locations for velocity sensors. Air speeds measured using the hot wire thermal anemometer at the centerlines between adjacent louver blades were similar in magnitude to air speeds measured at the louver outlet equidistant between adjacent louver blades. Also, at the louver outlet speeds were generally highest, as expected, at locations approximately equidistant from the adjacent louver blades. Thus, based on the visualization with smoke and the air speed mapping with the thermal anemometer, probes were installed equidistant from louver blades except the upper probe installed at the outlet face of the ELF375DX louver which was moved upward by 0.5 inch to capture the maximum air speeds.

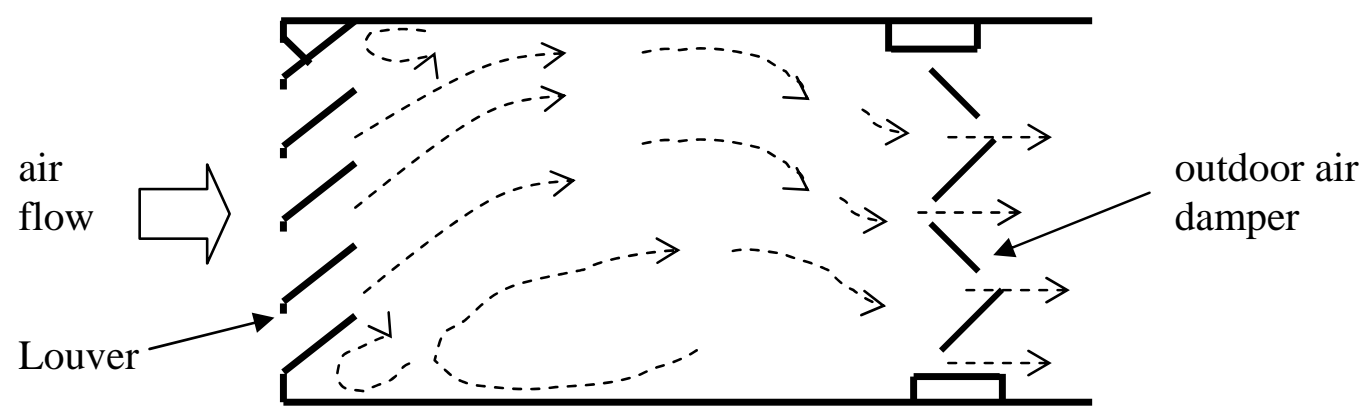

Figure 7. Example of airflow patterns inferred from visualization of smoke flow.

Objective 8. Perform visual observations of smoke flow to confirm that flow straighteners actually straighten the airflow.

In tests with airflow straighteners, the eddies depicted in Figure 7 sometimes extended through the airflow straighteners, thus, at some locations air flowed backwards through the airflow straightener toward the OA intake damper. Thus, the airflow was straightened only as it passed through the cells of the airflow straighteners. As discussed subsequently, the airflow straighteners did not result in a spatially uniform air speed at the locations of the downstream velocity sensors.

\subsection{Measurement quality objectives}

Objective 9. Confirm that test system leakage is less than 2 percent of the minimum air flow rates expected in practice.

The result of the leakage test of the experimental system was as follows. With the maximum system pressurization, which exceeds that encountered during subsequent experiments, the 
leakage rate was only 1.2 percent of the lowest $\mathrm{OA}$ flow rates measured during testing of OA flow measurement technologies.

Objective 10. Confirm that pressure differences measured with the electronic transducer, after calibration factors are applied as needed, are within \pm 0.008 inch of water of the pressures difference measured with the micromanometer.

The calibration of the pressure transducer used with the reference air flow meter was checked on three occasions using an electronic micromanometer as the calibration reference. Over a broad range in pressures, the error ranged from -1.3 to +0.5 percent of the measured pressure. In only one of 30 calibration points did the discrepancy of 0.009 inch of water exceed the \pm 0.008 inch of water target; however, a more appropriate target would have been having the percentage error less than \pm 5 percent of the measured pressure. This target was substantially exceeded.

Objective 11. Confirm that flow rates measured by the reference flow meter and by the Pitot tube traverse agree within 6 percent.

Before initiating tests of the OA measurement systems, flow rates measured with the reference flow meter were compared to flow rates measured via a standard Pitot tube traverse. The discrepancy between flow rates measured with these two methods varied from -1 percent to +2 percent of the measured flow rate.

\subsection{Research objectives}

Objective 12. The accuracy of OA flow measurements will be quantified for the various experimental configurations with velocity probes between louver blades or at the louver outlet using the following equation

$$
Q_{O A}=V_{A V G} K A_{\text {FREE }}
$$

where $Q_{O A}$ is the OA flow rate, $V_{A V G}$ is the average velocity from the electronic sensors, $K$ is a constant determined from test results, and $A_{F R E E}$ is the free area of the louver - a parameter provided by louver manufacturers. Determine the calibration factors; i.e., values of $\mathrm{K}$ in equation 1 , that best fit data from the experiments described above using probes in conjunction with louvers. Develop estimates of the errors in OA flow rate measurement resulting when a single value of $\mathrm{K}$ is used for a range of $\mathrm{OA}$ flow rates and when $\mathrm{K}$ obtained from experiments with one louver-probe combination is applied to a second version of the same louver type. Quantify the repeatability of accuracy estimates and $\mathrm{K}$ values from the repeated tests.

With velocity probes placed between louver blades or at outlet of louvers:

- the average measured air velocity was linearly related with the reference OA flow rate;

- prediction of OA flow rates using equation 1 was found to be inappropriate because the significant intercepts in the linear relationship of measured velocity with OA flow rate;

- using the average measured air velocities plus a slope and intercept obtained from the test data, OA flow rates were predicted with a maximum error of 12 percent, even with OA 
- errors in the predicted OA flow rate based on data from three or four velocity sensors were not significantly different from errors based on data from ten or 12 sensors;

- values of \%error from original and repeat tests were the same within 1 percent.

- calibration parameters obtained from tests using the first version of a louver resulted in accurate predictions of OA flow rates in tests of a second version of the same type of louver, suggesting that calibration equations from tests of a single louver may apply for all louvers with the same design, size, and velocity probe locations.

Figure 8 shows velocities measured with the EBTRON probes installed at the outlet face of louvers or between louver blades. These velocities are plotted versus values of $Q_{R E F}$ and the results of fitting linear equations to the data are provided. In all cases that data are very well fit by linear equations with $\mathrm{R}^{2}$ of 0.99 or 1.00 . The slopes (values of $m$ ) range from 0.75 to 1.02 and the intercepts (values of $b$ ) range from -60 to +61 but are generally positive. Average velocities from three of four sensors fall along the lines of average velocity measured using ten to 12 sensors.

Because the intercepts were often significant in magnitude relative to the lowest measured air velocities of approximately $100 \mathrm{fpm}$, application of equation 1 was inappropriate for estimating OA flow rates or associated errors. Consequently, equations 3, 4, and 5 were applied as described previously. Figure 9 shows values of \%error calculated from the test data. Errors ranged from -12 percent to +11 percent but were generally less than \pm 5 percent. All the error curves had a similar shape with the largest positive errors at intermediate flow rates suggesting that even smaller errors might be obtained by using non-linear equations fitted to the original data to calculate values of $Q_{P}$. Errors based on use of three of four velocity sensors werre not significantly different from errors obtained using ten to 12 sensors implying that only a few sensors are necessary to measure the OA flow rate through a 24 inch by 24 inch louver. Overall, the \%errors from tests with velocity probes at the louver outlet face were very similar in magnitude to \%errors from tests with velocity probes installed between louver blades.

As shown in the lower left chart of Figure 8, data from repeat tests were consistent with data from original tests. The slope of the best fit equations from original and repeat data differed by only 0.02 and the intercepts differed by only $11 \mathrm{fpm}$. As shown in the lower left chart of Figure 9, the errors from the original and repeat tests were the same within 1percent.

A second version of the Ruskin ELF 375DX louver was purchased and the velocity data (figure 8) obtained from tests with this second louver fell along the line of data obtained from tests of the first louver. In addition, values of system calibration parameters $m$ and $b$ obtained from tests of the first louver were used to predict the OA flow rates in the second version of this louver with no significant change in \%error (Figure 9) suggesting that system calibration parameters from tests of a single louver may apply for all louvers with the same design, size, and velocity probe locations. This finding was expected, given that the louver geometry and probe locations were essentially unchanged. 

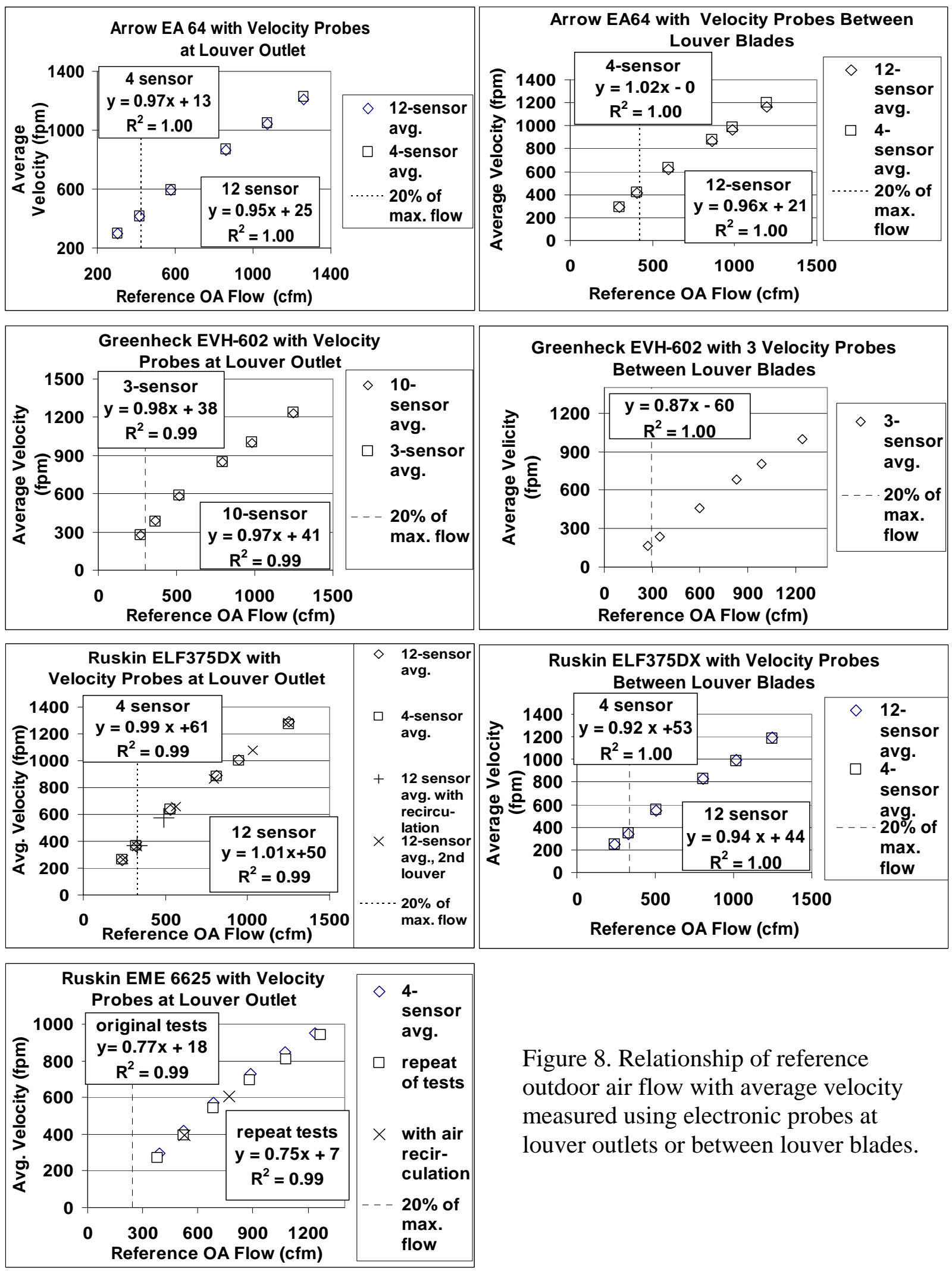

Figure 8. Relationship of reference outdoor air flow with average velocity measured using electronic probes at louver outlets or between louver blades. 

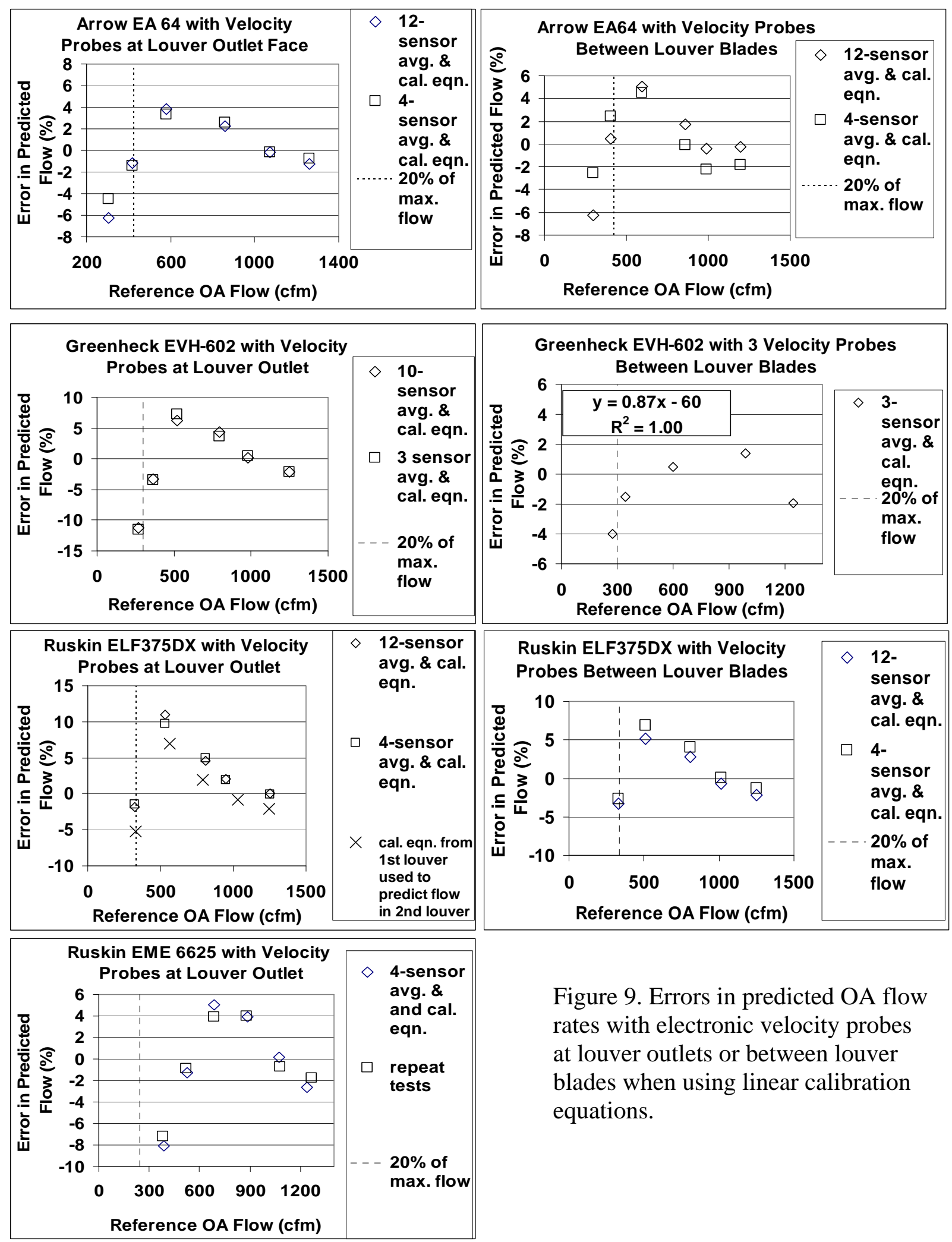

Figure 9. Errors in predicted OA flow rates with electronic velocity probes at louver outlets or between louver blades when using linear calibration equations. 
Objective 13. Quantify the accuracy of OA flow rate measurements for the various experimental configurations with airflow straighteners using the following equation

$$
Q_{O A}=V_{A V G} A_{\text {DUCT }}
$$

where $Q_{O A}$ is the OA flow rate, $V_{A V G}$ is the average velocity from the electronic sensors and $A_{D U C T}$ is the cross sectional area of the duct located between the air intake louver and OA damper where the airflow straightener and velocity sensors are installed.

With velocity probes installed downstream of airflow straighteners located in the duct system between the OA intake louver and the OA damper:

- the product of the average measured air velocity with duct cross section area (i.e., equation 2) resulted in errors in predicted OA flow rate as high as +100 percent and often larger than +25 percent;

- the errors in predicted OA flow rate varied substantially depending on the type of upstream OA louver;

- similar magnitude errors were obtained using a coarse and fine airflow straightener;

- air velocities downstream of the airflow straighteners were highly non uniform, thus, the estimated OA flow rates and the errors in these flow rates depended on the number and locations of velocity sensors;

- in most cases, errors in OA flow rate were not reduced by using airflow straighteners; and

- the average measured air velocity was linearly related with the reference OA flow rate suggesting that linear calibration equations would yield relatively accurate OA flow rates if accurate calibrations could be performed in field settings for each specific HVAC system.

Figure 10 shows the values of \%error obtained from tests with velocity probes installed downstream of airflow straighteners with and without an upstream louver. The three charts on the left are based on the velocity data from all nine velocity sensors, while the three charts on the right are based on data from only the central vertical row of three air velocity sensors. When data from all nine sensors were used and there was no upstream louver, \%error is approximately +20 percent to +30 percent. With upstream louvers, errors were sometimes larger and sometimes smaller, but were as high as +75 percent when data from all nine sensor were used and as high as $+100 \%$ when data from only three sensors were used. In all but few cases errors were positive (i.e., OA flow is over predicted) and the error often exceeded 25 percent. Errors varied substantially depending on the type of upstream louver with the location of probes and airflow straighteners unchanged. Errors tended to be slightly smaller when the fine airflow straightener was employed. Errors obtained with velocity probes located three inch, as opposed to five inch, downstream of the airflow straightener were not consistently larger or smaller in magnitude.

Tests using the Ruskin EME6625 louver and fine airflow straightener were repeated and the average \%error in the second set of tests was 6.6 percent less than in the first set of tests (Figure 10 ), which was significantly poorer than the 1 percent repeatability obtained in the previously discussed tests with probes at the louver outlet face. A slight misalignment of the OA louver when installed at the inlet of the OA duct was considered a possible cause for this poorer repeatability in results. In three pairs of tests, varying the angle of the OA louver relative to the 
OA duct by just a few degrees resulted in changes in \%error of 1, 4 and 6 percent. The tests with the Arrow EA64 louver with recirculation may be also be considered a repeat of the analogous tests without recirculation, if, as discussed below, recirculation does not affect measurement accuracy. The values of \%error from tests with and without air recirculation differed by less than 2 percent.
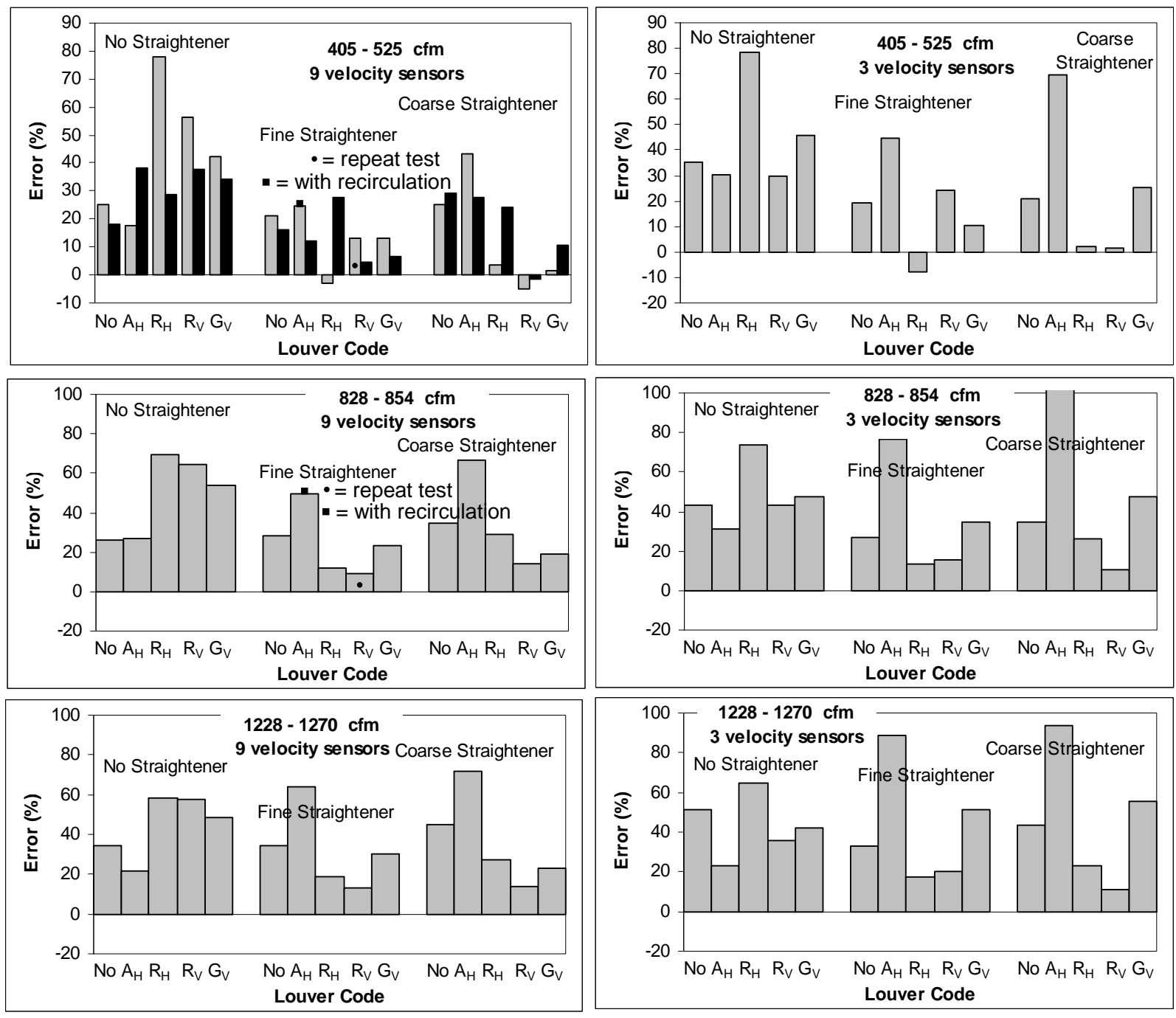

$$
\begin{array}{ll}
\text { Louver codes: } & \\
\text { No }=\text { no louver } & A_{H}=\text { Arrow EA64 } \quad R_{H}-\text { Ruskin ELF375DX } \\
\mathrm{R}_{\mathrm{V}}=\text { Ruskin EME6625 } & \mathrm{G}_{\mathrm{V}}=\text { Greenheck EVH602 }
\end{array}
$$
$\mathrm{A}_{\mathrm{H}}=$ Arrow EA64 $\quad \mathrm{R}_{\mathrm{H}}-$ Ruskin ELF375DX
$\mathrm{G}_{\mathrm{V}}=$ Greenheck EVH602

Figure 10. Results of tests using velocity probes with nine or three air velocity sensors located behind airflow straighteners, and for reference, behind no airflow straightener. In all experiments, the inlet of the flow straightener was located 5 to 6 inch behind the outlet of the louver (depending on the louver thickness) and sensors were located 3 inch (dark columns) or 5 inch (light columns) behind the outlet face of the airflow straightener. The distance between the sensors and centerline of the outdoor air damper was 9.5 inch (dark columns) or 45 inch (light columns). 
The measured air velocities downstream of the airflow straighteners, or at the same locations without an airflow straightener installed, were highly nonuniform. The ratio of maximum to minimum measured air velocity was often larger than an order of magnitude. The velocity profiles reflected the direction at which air exited the louvers. For example, consider a test with the Arrow EA64 louver, which directs air upward, with probes installed downstream of the fine airflow straightener, and with a reference OA flow rate of $840 \mathrm{cfm}$. The average velocity of the top row of sensors was $483 \mathrm{fpm}$ and the average velocity of the bottom row of sensors was only $12 \mathrm{fpm}$. The blockage of airflow by the frames of the louvers is another factor that may have caused the measured velocities to be non-uniform, particularly with the relatively small louvers used in the experiments. Thus, the airflow straighteners did not result in a spatially uniform air velocity at the location of the velocity sensors. As expected with such non-uniform velocities, the average velocity varied depending on the number of sensors utilized and their locations. The associated errors in OA flow rate predicted using equation 2 also varied depending on the number of sensors utilized and their locations. Figure 10 shows the errors obtained when the average velocity was based on only three sensors arranged in a vertical row was often larger than the errors with the average air velocity based on data from all nine sensors.

Figure 11 provides plots of average measured air velocity, using data from all nine EBTRON velocity sensors, versus reference air flow rate based on the tests with the probes located five inch downstream of the flow straightener and 50 inch of duct between the flow straightener and the centerline of the OA damper. In all cases the relationship of average velocity with reference flow rate was linear $\left(\mathrm{R}^{2}=1.00\right.$ when linear equations are fitted to the data); however, the slope resulting from the least squares fitting of a linear equations to the data varied with type of upstream louver and type of airflow straightener. The intercepts of the linear equations were often but not always moderate to small relative to the air velocities measured at the lower values of reference air flow rate. The linear relationships do suggest that outdoor air flow rates could be determined with reasonable accuracy if accurate system calibrations (as opposed to sensor calibrations) could be performed in field settings for each specific system. The average air velocities measured in these tests with probes downstream of airflow straighteners were smaller than the average air velocities at the same reference OA flow rates when the probes were between louver blades or at the outlet face of louvers.

Objective 14. Assess the change in accuracy, if any, in two OA flow measurement configurations, when air is recirculated.

- When air was recirculated, the accuracy of measuring OA flow rates did not change significantly.

The lower left chart of Figure 8 shows that velocity data collected with and without air recirculation, with probes at the louver outlet, fell along the same line. Application of equations 4 and 5 with the values of system calibration parameters $m$ and $b$ obtained from tests without air recirculation to the tests with recirculation resulted in values of \%error of -7.9 percent and -1.5 percent which fell within the range of values of \%error $(-8$ percent to +5 percent) from tests performed without any recirculation. In tests with velocity probes located downstream of airflow 
straighteners, values of \%error from analogous tests with and without air recirculation were equal within 2 percent (Figure 10).
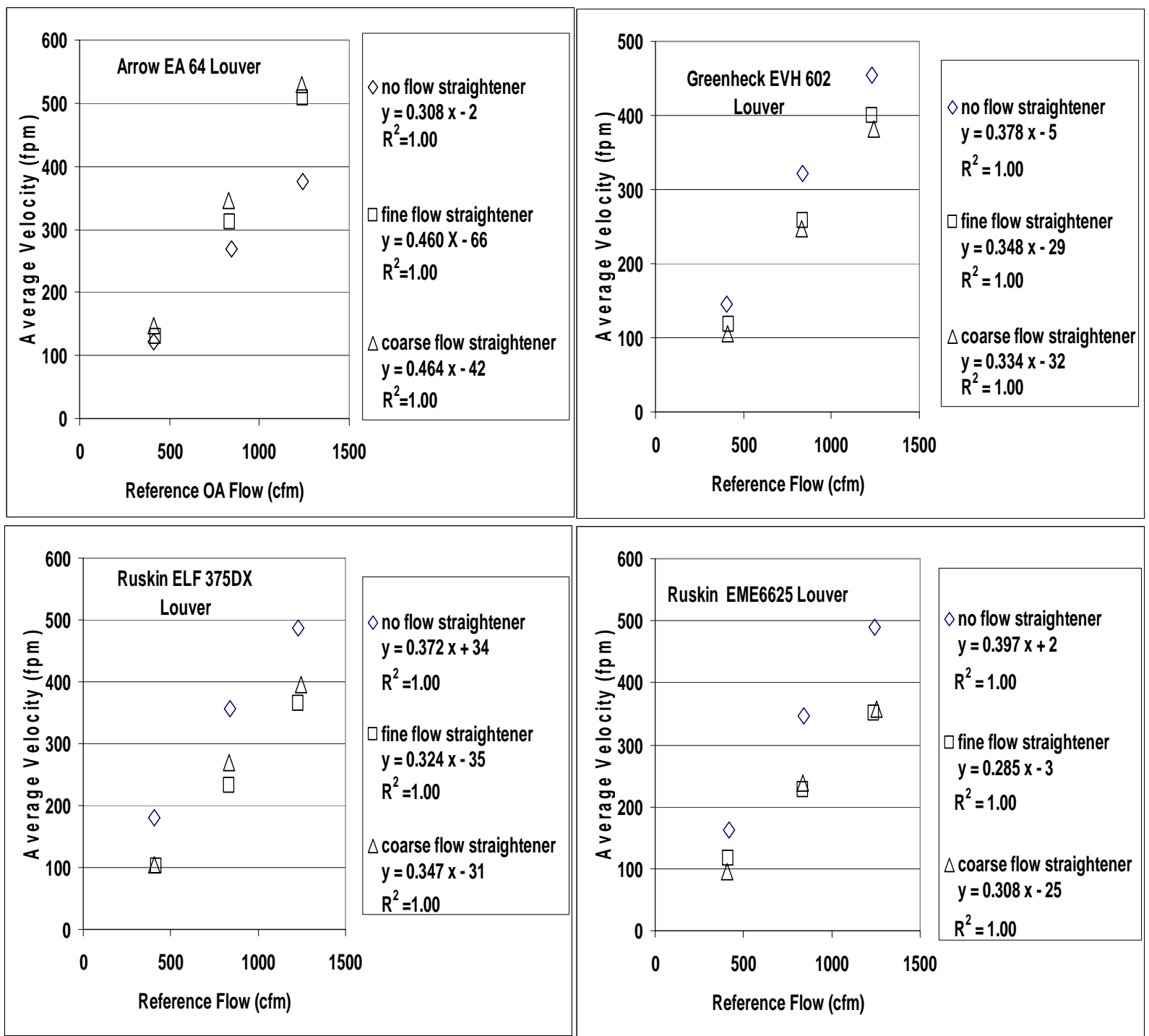

Figure 11. Average air velocity, using data from nine velocity sensors, versus reference flow from tests with airflow straighteners.

\subsection{Research Documentation and Communication Objectives}

Objective 15. Mail a report from this research to at least 20 HVAC firms and/or manufacturers of OA flow measurement technologies.

A summary version of this report was mailed to the individuals and organizations in the following table. 
Table 1. List of employers of the recipients of a summary report from this research project.

\begin{tabular}{|l|}
\hline \multicolumn{1}{|c|}{ Company or Organization } \\
\hline EBTRON Inc. \\
\hline Ruskin Inc. \\
\hline Trane \\
\hline Johnson Controls Inc. \\
\hline Schoen Engineering \\
\hline International Code Council \\
\hline SMACNA \\
\hline AHRI \\
\hline Bohanon Engineering \\
\hline Macmillan Engineering \\
\hline McQuay International \\
\hline Vital Air Technologies, Inc. \\
\hline Taylor Engineering \\
\hline Carrier Corp. \\
\hline Rumsey Engineers \\
\hline Michaels Engineering \\
\hline Federspiel Controls \\
\hline Paragon Controls \\
\hline Facility Diagnostics, Inc. \\
\hline Siemens Building Technology \\
\hline Goetting and Associates \\
\hline
\end{tabular}

Comments received from recipients of the summary report were mainly expressions of thanks or compliments on the paper. One recipient, who is contributing to the ASHRAE design guide for indoor air quality, asked if the report could be referenced to which an affirmative response was given.

Three additional technical comments from recipients were as follows:

- Recipients expressed an interest in how measurement accuracy persists over time. Related research was included among the subsequent recommendations.

- One recipient expressed a strong interest in how accuracy varied when the distance between the louver and OA damper became small for both parallel blade and opposed blade OA dampers. To minimize HVAC sizes, designers often seek to minimize the distance between the louver and the damper and at some small distance measurement accuracy would be expected to degrade because of how the damper affects the upstream airflow profile. An investigation of this issue was not within the project scope, but research was included among the subsequent recommendations. 
- One recipient expressed concern about measurement accuracy during periods of precipitation if the sensors become wet. This recipient recommended related research. This issue could be evaluated in the field studies recommended subsequently in this report.

Objective 16. Hold at least one in-person or conference call discussion with California Energy Commission staff responsible for related portions of Title 24.

The results of this research were discussed with Ms. Martha Brook of the California Energy Commission. Ms. Brook indicated her appreciation of the project and asked for clarification on a few issues. She recognized the need for public support for the follow-up research described in the subsequent recommendations. She indicated that she would like to see the OA flow measurement technology enter the market and suggested that CEC might consider a related specification for an accurate OA flow measurement system in a future reach standard, as this action could help to stimulate the necessary market demand.

\subsection{Discussion of project outcomes}

This research indicatees that OA flow rates should be measurable with errors generally less than 10 percent using electronic air velocity sensors installed between louver blades or at the outlet face of louvers. System calibration parameters " $m$ " and " $b$ " are required for each unique combination of louver type and velocity sensor locations. It is possible that the values of these system calibration parameters will also vary with louver size, but this possibility was not evaluated. High accuracy in measurement of OA flow rates is maintained with flow rates as low as 15 percent of the maximum recommended for the louver, corresponding to provision of 15 percent of outdoor air in the supply airstream at minimum OA supply conditions in HVAC systems with economizers. Thus, this measurement approach for OA flow rates does not require that HVAC systems have a separate OA intake section dedicated to minimum OA supply. Measurement accuracy is similar with velocity probes between louver blades or at the outlet face of louvers. Given that probe installation at the louver outlet face is simpler, this may be the preferred probe location particularly when the measurement system is added to existing HVAC systems. Application of this measurement approach depends on the development of system calibration parameter parameters (i.e., values of $m$ and $b$ ) and probe installation instructions and hardware by the velocity probe manufacturers or some other entity. However, because louvers geometries and probe installation locations are both highly repeatable, and given the results of our tests using a second version of one of the louvers, it seems unlikely that calibrations are necessary at building sites for each specific installation.

The research found that installation of two types of airflow straighteners did not, in general, improve the accuracy of measuring OA flow rates when the electronic velocity probes were installed in the duct system between OA intake louvers and OA damper. For the louver types and sizes employed, predicted OA flow rates based on the average measured air velocity and duct cross sectional area were often more than 25 percent greater than the "true" reference values of OA flow rate and the errors varied substantially depending on the type of upstream louver.

One of the advantages of placing the velocity probes between louver blades or at the immediate outlet of louvers, relative to downstream of airflow straighteners, is that the velocity is spatially 
more uniform at the first two probe locations. The percent relative standard deviation in velocity averaged 12 percent with the probes between blades or at the louver outlet while the percent relative standard deviation in velocity averaged 93 percent from measurements downstream of airflow straighteners when there was an upstream louver. It is difficult to capture a true average air velocity using a practical number of sensors when the air velocity is highly non uniform.

The cause of the general over prediction of OA flow rate in the measurements using airflow straighteners is not known; however, the presence of large scale eddies in the duct system downstream of louvers is a possible partial explanation. If the velocity sensors are located in the plane containing the eddy, the sensor system will detect air flowing both toward and away from the OA damper, while the OA flow rate calculation via equation 2 assumes that all air flows toward the OA damper. However, the OA flow rates are over-predicted with equation 2 even when no upstream louver is used, so this effect could only be a partial explanation. The sensor location is clearly very far from ideal for accurate air flow rate measurements because the long straight sections of ductwork needed to attain an ideal sensor location are impractical within the OA inlet sections of most HVAC systems. The velocity sensors were located approximately 0.8 of a hydraulic diameter from the entrance to the OA duct - a region in which the airflow profile is highly influenced by entrance effects -- while the recommended location of velocity measurements for determining air flow rates is at least 7.5 hydraulic diameters downstream of a section of straight ductwork (ASHRAE 2005). Also, the velocity sensors were located 0.2 hydraulic diameters downstream of the airflow straighteners while the recommended sensor location is approximately five hydraulic diameters downstream of airflow straighteners (ANSI/AMCA 2007).

The approximately 25 percent over-prediction of OA flow rate when the OA inlet section of the duct contained no louver or airflow straightener was initially surprising. Much of this discrepancy may be explained by three factors. First, the velocity probes obstruct 9.4 percent of the cross sectional area of the duct, increasing the air velocity at the location of the probes by 9.4 percent and resulting in a 9.4 percent over-prediction of OA flow rate. Second, the developing air velocity profile at the duct entrance is a partial explanation. For the range of air flow rates encountered in the experiments, fluid dynamics theory (White 1974) indicates that, at the plane of the velocity sensors, there is a region extending approximately one inch from the duct walls in which air velocities are substantially diminished relative to the centerline velocity. All of the velocity sensors were located further than one inch from duct walls, so the sensor system totally misses the region of lower air velocity. The one inch thick region with a diminished air velocity represents approximately 15 percent of the total cross sectional area of the duct system. If one assumes the air velocity in this region is, on average, approximately half of the centerline velocity, then 7.5 percent (one half of 15 percent) of the over-prediction is explained by the developing air velocity profile. Another 5 percent of the discrepancy would be explained if the velocity sensors do, in fact, indicate an average, a velocity $5 \%$ larger than the true velocity, as suggested by the calibration checks discussed previously. Thus, approximately 16.9 percent (9.4 percent plus $7.5 \%$ ) to $21.9 \%$ (if the sensors read 5 percent high) of the 25 percent discrepancy is explainable.

The errors in OA flow rate measurements in systems using airflow straighteners may be significantly smaller in systems with larger OA intake sections than employed in this research 
because the edge effects on airflow patterns would be reduced. For example, the frames at the perimeter of the OA intake louvers blocked a substantial portion of the inlet of the 24 inch by 24 inch duct, but louver frames would block a smaller portion of the duct when larger louvers are used. The research did demonstrate a linear relationship between average measured velocity and reference OA flow rate, suggesting that accurate measurements of OA flow rate should be obtainable with this measurement approach if accurate system calibrations can be performed in field settings for each specific air intake system. It may even be possible to obtain accurate OA flow rates based on laboratory calibrations that account for each specific combination of louver type and size and on the location of velocity sensors in the duct system relative to the location of the louver and OA damper; however, no data were collected to assess this possibility. Also where sufficient straight duct is available so that sensors can be installed away from the zones of influence of the OA louver and damper, then simply multiplying average measured velocity with duct area may yield accurate values of OA flow rate, as the sensors themselves were quite accurate.

A number of limitations to this program of research should be mentioned. First, as mentioned above the research utilized only one size of louver. Although, the general findings of this research are very likely to apply for larger louvers, it would be desirable to obtain similar data with larger louvers. Second, the present research involved only a few months of testing in an indoor location, thus, it did not assess whether measurement accuracy would be maintained for longer periods with the probes exposed to outdoor air that varies in temperature and moisture content and that can contain more particulate matter. Third, the tests were performed in a setting without wind which, in theory, may influence the pattern of airflow through louvers and the measurement accuracy. However, in prior field studies of other OA measurement systems (Fisk et al. 2005c), wind speed or direction did not substantially affect measurement accuracy. Fourth, this research employed only EBTRON air velocity sensors; hence, the findings are strictly applicable only for EBTRON sensors. However, other manufacturers may be able to provide electronic sensors that accurately measure air speed over the same range and that can be used as described above to measure OA flow rates.

\subsection{Conclusions and Recommendations}

\subsection{Conclusions}

The use of electronic air velocity probes between the blades of OA intake louvers or at the outlet face of louvers is highly promising as a means of accurately measuring the rates of OA flow into HVAC systems. The expected measurement errors are, in most cases, less than 10 percent. System calibration parameters are required for each unique combination of louver type and velocity sensor locations, but calibrations do not appear to be necessary for each measurement system installation. High accuracy, is attainable even with OA flow rates as low as 15 percent of the maximum recommended flow rate for the louver. Thus, this measurement approach for OA flow rates does not require that HVAC systems have a separate OA intake section dedicated to minimum OA supply. If suitable system calibration parameters are provided by sensor manufacturers, this measurement approach should be applicable to both new and existing HVAC systems. 
Installation of two types of airflow straighteners did not improve the accuracy of measuring OA flow rates when the electronic velocity probes were installed in the duct system between OA intake louvers and OA dampers. For the louver types and sizes employed, predicted OA flow rates based on the average measured air velocity and duct cross sectional area were often more than 25 percent greater than the "true" reference values of OA flow rate and the errors varied substantially depending on the type of upstream louver. Thus, at least for the relatively small 24 inch by 24 inch air intake sections employed in this research, this measurement approach is considerably less promising than use of electronic air velocity probes between the blades of OA intake louvers or at the outlet face of louvers.

\subsection{Recommendations}

Field studies are recommended to assess the long term accuracy of OA flow rate measurements using velocity probes installed between the blades of OA intake louvers and at the outlet face of louvers and to evaluate accuracy during periods of precipitation. These field tests will also serve as a technology demonstration that will help to build demand for technology commercialization. The testing must be performed in settings where highly accurate reference measurements of OA flow rates are feasible. Tests with a few different louver types and climates are desirable. Outdoor wind speeds and directions should be logged so that the effects of wind on measurement accuracy can be evaluated.

Limited further laboratory tests are recommended to determine how measurement accuracy varies when the distance between the louver and OA damper is decreased. This research should be performed with velocity probes installed between louver blades and also at the outlet face of the louver and with both parallel-blade and opposed-blade OA dampers. When the louver becomes very close to the OA damper, the measurement accuracy would be expected to degrade because of how the damper affects the upstream airflow profile. HVAC designers often seek to minimize the distance between louvers and OA dampers as part of efforts to minimize HVAC size; thus, this recommended research would be of value to both HVAC designers and those contemplating use of the investigated OA measurement technologies.

Test are recommended to determine if the system calibration parameters $m$ and $b$ required for accurate determination of OA flow rates vary with louver size.

Commercial application of the results of this research depends upon the development of system calibration parameters for various types of louvers and sensor locations. The development of these calibration parameters and the development of suitable probe installation hardware is recommended to the private sector, e.g. to manufacturers of suitable velocity sensors. Once the test system and protocols are established, only a few hours of testing will be required for each unique type of louver-probe combination.

\subsection{Public Benefits to California}

This research has identified a highly promising approach for accurately measuring OA flow rates into existing and new commercial building heating, ventilating, and air conditioning systems. 
This measurement approach could be used in conjunction with existing building control systems to improve the control of the amount of OA ventilation provided to buildings. If the measurement approach is commercialized and significantly deployed, the resulting improvements in control of building ventilation rates will save energy, because most existing buildings appear to be over-ventilated relative to code requirements and because the thermal conditioning of ventilation air consumes energy. The energy savings will help California achieve its goal of reducing emissions of greenhouse gases. In addition, improved indoor air quality and occupant health are expected when the measurement technology is utilized in buildings that are currently under ventilated relative to code requirements.

The technical potential energy savings, i.e., maximum possible energy savings with full deployment, from commercialization and use of this technology was estimated; however, this estimate is highly uncertain primarily because of the absence of data on minimum OA ventilation rates in California's commercial buildings. There following assumptions underlie the estimate of technical potential energy savings:

- the technology is applied in all California commercial building HVAC systems with a cooling capacity greater than 10 tons, which represents 43 percent of the total installed cooling capacity (Jacobs 2003);

- the current average minimum OA ventilation rate where the technology is applied is 187 percent of the minimum ventilation rate specified in Title 24 standards;

- for buildings in which the technology is applied, after application, the average minimum OA ventilation rate equals the rate specified in Title 24 standards; and

- nineteen percent of space heating and cooling energy is used for heating and cooling of air provided for outdoor air ventilation.

The second and forth assumptions in the prior list are based on rough analyses by Fisk (2005a) which relied on minimum ventilation rate estimates from a survey of a representative sample 100 U.S. medium to large office buildings. Using data from this survey, Fisk (2005a) estimated that the average minimum ventilation rate in the offices was $28 \mathrm{cfm}$ per occupant, which is 165 percent of the minimum ventilation rate for offices in the current ASHRAE commercial ventilation standard (ASHRAE 2007) and 187 percent of the minimum ventilation for offices in Title 24. No comparable data are available from U.S. commercial buildings other than offices and no significant set of representative data are available from California commercial buildings. With these assumptions and estimates from ITRON (2006) that California's commercial buildings annually use 18,100 GWh of electricity and 460 million therms of gas for space heating and cooling, the annual technical potential energy savings is $780 \mathrm{GWh}$ of electricity and 20 million therms of gas.

\subsection{References}

ANSI/AMCA (2007). ANSI/AMCA 210-07 and ANSI/ASHRAE 51-07. Laboratory methods of testing fans for certified aerodynamic performance rating, Air Movement and Control Association. Inc. Arlingtom Heights, IL and American Society of Heating, Refrigerating, and Air Conditioning Engineers, Atlanta. GA.

ASHRAE (2005). 2005 ASHRAE Handbook, Fundamentals, Chapter 14. Atlanta, GA, American Society of Heating, Refrigerating, and Air Conditioning Engineers, Inc. 
ASHRAE (2007) ANSI/ASHRE Standard 62.1-2007 Ventilation for acceptable indoor air quality. American Society of Heating, Refrigerating, and Air Conditioning Engineers, Atlanta. GA

CARB (2004). Report to the California Legislature: Environmental health conditions in California’s portable classrooms, California Air Resources Board and California Department of Health Services.

Department of Energy (2006). 2006 Buildings energy databook. Washington, D.C., U.S. Department of Energy.

Fisk, W. J., D. Faulkner and D. P. Sullivan (2004). An evaluation of technologies for real-time measurement of rates of outdoor airflow into HVAC systems, LBNL-56397. Berkeley, CA, Lawrence Berkeley National Laboratory.

Fisk, W. J., D. Faulkner and D. P. Sullivan (2005a). "An evaluation of three commercially available technologies for real-time measurement of rates of outdoor airflow into HVAC systems." ASHRAE Transactions 111(2): 443-455.

Fisk, W. J., D. Faulkner and D. P. Sullivan (2005b). "Technologies for measuring flow rates of outdoor air into HVAC systems: some causes and suggested cures for measurement errors." ASHRAE Transactions 111(2): 456-463.

Fisk, W. J., D. Faulkner and D. P. Sullivan (2005c). Real-time measurement of rates of outdoor airflow into HVAC systems: a field study of three technologies. LBNL 58856. Berkeley, CA, Lawrence Berkeley National Laboratory.

Fisk, W. J., D. Faulkner and D. P. Sullivan (2006). Accuracy of $\mathrm{CO}_{2}$ sensors in commercial buildings: a pilot study LBNL-61862. Berkeley, CA.

ITRON (2006). California commercial energy use. Report CEC-400-2006-005 for the California Energy Commission.

Jacobs, P. (2003) Small HVAC field and survey information. California Energy Commission report 500-03-082-A-23 prepared bt the Architectural Energy Corporation, Boulder, CO.

Kettler, J. P. (1995). "Minimum ventilation control for VAV systems: fan tracking versus workable solutions." ASHRAE Transactions 101(2): 625-630.

Kettler, J. P. (2000). "Measuring and controlling outdoor airflow." IAQ Applications Winter 2000.

Seppanen, O. and W. J. Fisk (2006). "Some quantitative relations between indoor environmental quality and work performance or health." International Journal of HVAC\&R Research 12(4): 957-973.

Seppanen, O. A., W. J. Fisk and M. J. Mendell (1999). "Association of ventilation rates and $\mathrm{CO}_{2}$ concentrations with health and other responses in commercial and institutional buildings." Indoor Air 9(4): 226-52.

Wargocki, P. and D. P. Wyon (2007). "The effect of moderately raised classroom temperatures and classroom ventilation rate on the performance of schoolwork by children." HVAC\&R Research 13(2): 193-220.

White, F. M. (1974). Chapter 6. Incompressible turbulent mean flow. Viscous Fluid Flow. New York, McGraw Hill.

Womble, S. E., E. L. Ronca, J. R. Girman and H. S. Brightman (1996). Developing baseline information on buildings and indoor air quality (BASE'95). IAQ'96 Paths to Better Building Environments. Baltimore, MD, ASHRAE: 109-117. 


\subsection{Development Status Questionnaire}




\section{California Energy Commission \\ Building Energy Research Grant (BERG) Program \\ PROJECT DEVELOPMENT STATUS}

\section{Questionnaire}

Answer each question below and provide brief comments where appropriate to clarify status. If you are filling out this form in MS Word the comment block will expand to accommodate inserted text.

\section{Please Identify yourself, and your project: PI Name William Fisk Grant \# 54915A0603B}

\section{Overall Status}

\section{Questions}

1) Do you consider that this research project achieved the goal of your concept?

2) Do you intend to continue this development effort towards commercialization?

\section{Comments:}

Briefly state why.

Yes, the project met the objective of identifying a technology for accurate and practical measurements of outdoor air flow rates into existing and new commercial HVAC systems

If funding is available, we would be very interested in performing the recommended field studies that assess long term measurement accuracy and effects of wind on accuracy and that serve as a technology demonstration to increase market demand. However, we believe that industry should ideally be responsible for the testing needed to develop the required calibration parameters and probe installation kits.

\section{Engineering/Technical}

3) What are the key remaining technical or engineering obstacles that prevent product demonstration?
4) Have you defined a development path from where you are to product demonstration?

5) How many years are required to complete product development and demonstration?
Few significant technical or engineering obstacles to commercialization remain. The sensors are already available. The primary need is for sensor installation kits and calibration parameters for each specific combination of louver and sensor locations, starting with the most commonly used louvers. The remaining technical uncertainty is a determination of whether measurement accuracy is maintained over many years - this is likely depends primarily on the stability of the velocity sensor calibrations. The other significant technical uncertainty is the accuracy of measurements under conditions with wind. Although prior research suggests that wind will have only a small effect on accuracy, the effects of wind should be checked.

One of the recommendations in the report is a set of field studies that serve to assess accuracy over time, the effects of wind on accuracy, and to simultaneously serve as technology demonstrations.

If the lingering uncertainties about long term measurement accuracy and the effects of wind on accuracy are neglected, our guess is that commercial products could be available with a year, but industry can better answer this question. Tests of accuracy over time would require several years of low level research, but manufacturers could decide to commercialize the measurement approach before those tests are completed. Many existing measurement technologies are commercialized without published data on long term accuracy. 
6) How much money is required to complete engineering development and demonstration?

7) Do you have an engineering requirements specification for your potential product?
Industry should assume the modest engineering development costs. Multi-site demonstrations that also assess how accuracy varies over time and with winds could be performed for a few hundred thousand dollars. No, development of such a specification was not part of the project scope and could be performed by industry.

10) Have you surveyed potential customers for interest in your product?

8) What market does your concept serve?

Marketing

9) What is the market need?

There must be a demand for technology utilization. Title 24 and ASHRAE standards could help stimulate that demand, as could technology demonstrations and advertisements by industry.

No, such a survey was not part of the project scope

11) Have you performed a market analysis that takes external factors into consideration?

12) Have you identified any regulatory, institutional or legal barriers to product acceptance?

13) What is the size of the potential market in California for your proposed technology?

No, such an analysis was not part of the project scope

We are aware of no such barriers.

The technology could be used as a retrofit, or in new construction, for a large fraction of the commercial HVAC systems in California. The application of the technology, particularly its cost effectiveness, for small rooftop HVAC is probably the most uncertain. The project scope did not include any assessment of the potential market size.

14) Have you clearly identified the technology that can be patented?

We do not believe that the basic measurement approach is not patentable. Specific probe installation systems may be marketable, but were not the focus of the project.

15) Have you performed a patent search? No, see above.

16) Have you applied for patents?

No, see above.

17) Have you secured any patents?

No, see above

18) Have you published any paper or publicly disclosed your concept in any way that would limit your ability to seek patent protection?

No, but see above.

\section{Commercialization Path}

19) Can your organization commercialize your product without partnering with another organization?

20) Has an industrial or commercial company expressed interest in helping you take your technology to the market?

21) Have you developed a commercialization plan?

No, we do not see a role for $L B N L$ in commercialization of this technology

No, see above

No, see above

22) What are the commercialization risks?

Analyses of commercialization risks was not within the project scope. 
23) If you plan to continue development of your concept, do you have a plan for the required funding?

24) Have you identified funding requirements for each of the development and commercialization phases?

25) Have you received any follow-on funding or commitments to fund the follow-on work to this grant?

26) What are the go/no-go milestones in your commercialization plan?

27) How would you assess the financial risk of bringing this product/service to the market?

28) Have you developed a comprehensive business plan that incorporates the information requested in this questionnaire?

\section{Public Benefits}

29) What sectors will receive the greatest benefits as a result of your concept?

30) Identify the relevant savings to California in terms of kWh, cost, reliability, safety, environment etc.

31) Does the proposed technology reduce emissions from power generation?

32) Are there any potential negative effects from the application of this technology with regard to public safety, environment etc.?

Commercial buildings sector.

Calculations of savings was not within the project scope

Yes, emission are reduced to the degree that any energy savings technology reduces such emissions. Estimating of the magnitudes of emission reductions was not within the project scope.

The public health effects will depend on how the technology is used. The technology itself poses no risks. If the technology led to wide scale reductions in commercial building ventilation rates to levels that adversely affected occupant health, public health would be adversely affected. In other settings, if the technology was used to increase ventilation rates in otherwise under ventilated buildings, health would be improved. We believe that ventilation standards are the proper vehicle for selecting the minimum ventilation rates that strike a balance between health and energy concerns and this technology will make it easier to adhere to such standards.

\section{Competitive Analysis}

33) What are the comparative advantages of your product (compared to your competition) and how relevant are they to your customers?

34) What are the comparative disadvantages of your product (compared to your competition) and how relevant are they to your customers?
Higher measurement accuracy without requiring a separate outdoor air intake system for the minimum outdoor airflow.

Unnecessary to perform a system calibration in field settings, i.e., at building sites.

Potential to be used in retrofit applications.

The technology relies on electronic air velocity sensors while most existing airflow measurement systems rely on pressure based velocity sensors. Electronic velocity sensors may be more subject to calibration shifts caused by deposition of dust on sensors and by corrosion of sensors.

Probe installation is more complex than with some existing technologies, but those existing technologies are subject to larger measurement errors. 
The BERG Program may in the future provide follow-on services to selected Awardees that would assist them in obtaining follow-on funding from the full range of funding sources (i.e. Partners, PIER, NSF, SBIR, DOE etc.). The types of services offered could include: (1) intellectual property assessment; (2) market assessment; (3) business plan development etc.

35) If selected, would you be interested in receiving We would be interested in receiving funding for the development assistance? recommended field studies and demonstrations. Industry is the appropriate recipient of assistance for the commercialization-related assistance described above. 